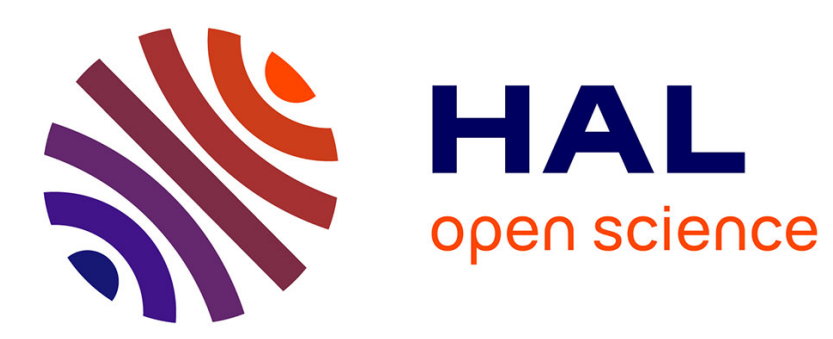

\title{
Jarres, terrailles, faïences et porcelaines dans l'Empire ottoman (XVIIIe-XIXe siècles)
}

Véronique François

\section{To cite this version:}

Véronique François. Jarres, terrailles, faïences et porcelaines dans l'Empire ottoman (XVIIIe-XIXe siècles). Turcica : revue d'études turques, 2008, 40, pp.81-120. 10.2143/TURC.40.0.2037136 . halshs00505407

\section{HAL Id: halshs-00505407 https://shs.hal.science/halshs-00505407}

Submitted on 23 May 2017

HAL is a multi-disciplinary open access archive for the deposit and dissemination of scientific research documents, whether they are published or not. The documents may come from teaching and research institutions in France or abroad, or from public or private research centers.
L'archive ouverte pluridisciplinaire HAL, est destinée au dépôt et à la diffusion de documents scientifiques de niveau recherche, publiés ou non, émanant des établissements d'enseignement et de recherche français ou étrangers, des laboratoires publics ou privés. 


\section{JARRES, TERRAILLES, FAÏENCES ET PORCELAINES EUROPÉENNES DANS L'EMPIRE OTTOMAN (XVIII ${ }^{\mathrm{e}}$-XIX ${ }^{\mathrm{e}}$ SIÈCLES)}

es connaissances sur la vaisselle, fabriquée et commercialisée dans l'Empire ottoman, sont encore lacunaires ${ }^{1}$. Assez peu de choses sont connues sur les céramiques répondant aux nécessités domestiques habituelles, qu'il s'agisse de la vaisselle culinaire, de service et de table ou des pots et jarres de stockage et de transport ${ }^{2}$. Ces ustensiles de terre sont encore trop souvent délaissés sur les chantiers de fouille même si,

Véronique FrançoIs est chargée de recherche au Laboratoire d'archéologie médiévale méditerranéenne, Aix-en-Provence

vfrancois@mmsh.univ-aix.fr

1 U. Baram, L. Caroll (eds.), A Historical Archaeology of the Ottoman Empire, Kluwer Academic / Plenum Publishers, 2000; F. YENIȘEHIRLIOĞLU, «L'archéologie historique de l'Empire ottoman. Bilan et perspectives », Turcica 37, 2005, p. 245-266; V. FRANÇOIS, «Tabak, ibrik, fincan et autres pots d'époque ottomane au Bilâd al-Châm», idem, p. 281-308; J. VRoom, «Kütahya between the Lines: Post-Medieval Ceramics as a Source of Historical Information», in S. DAVIES, J.L. DAVIS (eds.), Between Venice and Istanbul: Colonial Lanscapes in Early Modern Greece, Hesperia Supplement 40, 2007, p. 69-91.

2 J.W. Hayes, Excavations at Saraçhane in Istanbul, volume II : the Pottery, Princeton, 1992; V. FrAnÇOIS, «Eléments pour l'histoire ottomane d'Aphrodisias: la vaisselle de terre», AnatAnt, IX, 2001, p. 147-190; V. BIKIĆ, Gradska keramika Beograda (1617.vek) - Belgrade Ceramics in the $16^{\text {th }}-17^{\text {th }}$ Century, Belgrade, 2003; I. GERELYES, G. KovÁcs (eds.), Archaeology of the Ottoman Period in Hungary, Budapest, 2003; V. FrançoIs, Céramiques d'époques mamelouke et ottomane à la citadelle de Damas, édition numérique, Aix-en-Provence (envoi gratuit sur demande à vfrancois@mmsh. univ-aix.fr). 
ces dernières années, des travaux archéologiques menés en Grèce, en Turquie, en Serbie, en Hongrie et en Syrie-Palestine, ont contribué à l'élaboration de typologies permettant, lorsqu'elles se seront multipliées, de distinguer, par périodes chronologiques et par centres de fabrication, les productions ottomanes. Si la vaisselle utilisée sur les territoires de l'Empire est négligée, le matériel tardif est l'objet d'une discrimination supplémentaire. En effet, les fragments d'assiettes et de plats des XVIII et $\mathrm{XIX}^{\mathrm{e}}$ siècles sont ignorés parce que trop récents et peu nombreux. Parmi eux, les rares représentants des grandes manufactures européennes apparaissent comme des pièces exceptionnelles dont la présence sur les sites relève de l'anecdotique, témoignant plus du passage d'Occidentaux en ces lieux que d'un commerce organisé. Si les données livrées par le terrain sont encore insuffisantes pour obtenir une image précise du négoce de ces objets dans l'Empire, les documents statistiques, les rapports des Expositions universelles, les documents consulaires, les «entrées » et les «sorties » des grands ports méditerranéens ainsi que les archives des manufactures européennes permettent de repérer les pays producteurs, d'appréhender les volumes et les prix des céramiques commercialisées, de connaître les ports d'embarquement, de transit et de débarquement, et de préciser les modes de diffusion. À partir de l'exploitation de ces archives commerciales, la présence, sur les territoires de la Sublime Porte, de faïences fines, de porcelaines mais aussi de simples terres cuites produites dans les fabriques d'Europe, aux $\mathrm{XVIII}^{\mathrm{e}}$ et $\mathrm{XIX}^{\mathrm{e}}$ siècles, prend une tout autre ampleur.

Pour l'époque ottomane tardive, M. Milwright a mis en perspective les rapports consulaires français du Levant avec le matériel archéologique trouvé au Bilâd al-Châm. Il a ainsi pu dresser un tableau des importations de vaisselle étrangère au Proche-Orient de 1700 à $1918^{3}$. Pour ma part, j'ai choisi de traiter ce même sujet pour la Turquie d'Europe et la Turquie d'Asie ainsi que pour les îles de l'Egée. Contrairement à ce que les découvertes de terrain laissent croire, la présence de vaisselle européenne sur ces territoires n'est pas marginale. Ce sont en fait des volumes importants qui sont importés d'Europe. Il reste à identifier ces produits, ce que je tenterai de faire à partir des textes et du matériel archéologique.

3 M. Milwright, «Imported Pottery in Late Ottoman Bilad al-Sham: Preliminary Observations on the Archaeological and Historical Evidence», Turcica 40, p. 121-152. 
Plusieurs types de documents rendent compte, pour la Roumélie, l'Anatolie et l'Egée, de la commercialisation à grande échelle de diverses productions européennes désignées par les termes de faïence, porcelaine, poterie et terraille.

Pour la première moitié du $\mathrm{XIX}^{\mathrm{e}}$ siècle, les travaux de savants européens, qui livrent des renseignements économiques et administratifs sur l'Empire, évoquent parfois le commerce de la vaisselle. Ainsi entre 1830 et 1856, d'après J. de Saint-Denys, A. Ubicini et A. Visquenel, la France exportait vers la Turquie des poteries grossières et fines, bon marché, des faïences et de la porcelaine plus coûteuses (tableau 1). Et l'Angleterre, seulement mentionnée en 1856, fournissait de la poterie et des porcelaines. Le géologue A. Boué, après avoir fait de nombreux voyages en Turquie d'Europe, prétendait effectivement que «le pays reçoit de l'étranger, la plus grande partie de sa poterie, de sa faïence et de ses porcelaines en général grossières, toute sa verrerie et verroterie... la faïence est en bonne partie anglaise, et s'introduit des villes maritimes jusqu'au centre de la Turquie. La porcelaine vient surtout d'Autriche et d'Angleterre ${ }^{4}$.

Pour la fin du XIX ${ }^{e}$ siècle, les archives qui renseignent sur ce négoce sont: les comptes rendus de la Chambre de commerce française de Constantinople assortis de statistiques qui présentent des listes par volume et par prix des marchandises faisant l'objet d'un commerce au long cours; les statistiques livrées par V. Cuinet, secrétaire général de la Dette publique ottomane et membre actif de la Chambre de commerce française de Constantinople ${ }^{5}$; les rapports des Expositions Universelles qui précisent la qualité des productions de vaisselle européenne en concurrence et fournissent des renseignements chiffrés sur leur commercialisation; les archives des manufactures d'Europe.

La compilation des notes statistiques établie par V. Cuinet pour l'Empire ottoman à la fin du XIX ${ }^{\mathrm{e}}$ siècle ainsi que les comptes rendus de

\footnotetext{
${ }^{4}$ A. BouÉ, La Turquie d'Europe ou observations sur la géographie, la géologie, l'histoire naturelle, la statistique, les mœurs, les coutumes, l'archéologie, l'agriculture, l'industrie, le commerce, les gouvernements divers, le clergé, l'histoire et l'état politique de cet empire, Paris, Ar. Bertrand, 1840, tome III, p. 165-166.

${ }^{5} \mathrm{~V}$. CUINET, La Turquie d'Asie, géographie administrative statistique descriptive et raisonnée de chaque province de l'Asie Mineure, vol. I-XI, 1890-1894.
} 


\begin{tabular}{|c|c|c|c|c|}
\hline Date & Produits & Pays exportateurs & Valeur en franc & Poids en kg \\
\hline \multirow[t]{3}{*}{$\begin{array}{l}1830- \\
1840^{6}\end{array}$} & $\begin{array}{l}\text { Poterie grossière } \\
\text { et faïence }\end{array}$ & France & 29600 & 74000 \\
\hline & Poterie fine & France & 18000 & \\
\hline & Porcelaine & France & 45000 & 9000 \\
\hline $1839^{7}$ & $\begin{array}{c}\text { Poterie, } \\
\text { verres et cristaux }\end{array}$ & France & 694000 & \\
\hline $1853^{8}$ & $\begin{array}{c}\text { Poterie, } \\
\text { verres et cristaux }\end{array}$ & France & 530409 & \\
\hline \multirow[t]{2}{*}{$1856^{9}$} & $\begin{array}{c}\text { Poterie, } \\
\text { verres et cristaux }\end{array}$ & France & 1304881 & 1710823 \\
\hline & $\begin{array}{l}\text { Poterie de terre } \\
\text { et porcelaine }\end{array}$ & Angleterre & 1052225 & \\
\hline
\end{tabular}

TABLEAU 1. Exportations de vaisselle de France et d'Angleterre, entre 1830 et 1856, vers la Turquie

la Chambre de commerce française de Constantinople rendent compte de la pénétration de vaisselle étrangère, entre 1888 et 1892, (tableau 2 et carte) : - en Roumélie, au travers du port de Thessalonique et à Monastir (Bitola) en Macédoine; de Dédéagatch (Alexandroupolis), un port de Thrace orientale situé en face de l'île de Samothrace, sur la ligne de chemin de fer reliant Thessalonique à Constantinople; d'Andrinople (Edirne) en Thrace orientale; et de Constantinople; — en Anatolie, au travers des ports de Samsoun et Trébizonde en mer Noire; d'Aïvaly (Ayvalık), un port de la côte éolienne situé à $150 \mathrm{~km}$ au nord d'Izmir; de Smyrne (Izmir); d'Alexandrette (Iskenderun) dans la province de Syrie; — dans les îles de l'Egée telles que Candie, Samos et Rhodes. La valeur de ces marchandises est exprimée en franc et les volumes sont

6 Juchereau de SAINT-DenYs, Histoire de l'Empire ottoman depuis 1792 jusqu'en 1844, Paris, Imprimeurs Unis, 1844, p. 426.

7 A. UBICINI, Lettres sur la Turquie ou tableau statistique, religieux, politique, administratif, militaire et commercial, etc. de l'Empire ottoman. Depuis le Khatti-Cherif de Gulkhanè (1839), $2^{\mathrm{e}}$ éd. entièrement refondue et accompagnée de pièces justificatives, Paris, J. Dumaine, 1853-1854, 2 pars. IX-594 p. 294.

8 A. Visquenel, Voyage dans la Turquie d'Europe. Description physique et géologique de la Thrace. Ouvrage publié sous les auspices de M. le Ministre de l'Instruction publique. Paris, A. Bertrand, ED., 1868, p. 388.

9 X. Heuschling, L'Empire de Turquie. Territoire. Population. Gouvernement. Finances. Industrie agricole, manufacturière et commerciale. Voies de communication. Armée. Culte, etc. Suivi d'un appendice contenant le texte des traités et conventions cités dans l'ouvrage, Bruxelles, H. Tarlier, Paris, Guillemin et Ce ${ }^{\mathrm{e}}$ 1860, p. 183, 186. 
comptabilisés en $\mathrm{kg}$, en colis, en caisse, en tonneaux, en pièce et en unité $^{10}$. Parfois seule la valeur ou le volume sont mentionnés. L'estimation relative par port d'entrée dans l'Empire est donc impossible à établir.

\begin{tabular}{|c|c|c|c|c|c|}
\hline Port d'arrivée & Date & Produits & Pays exportateurs & $\begin{array}{c}\text { Valeur en } \\
\text { franc }\end{array}$ & $\begin{array}{l}\text { Unités de } \\
\text { mesure }\end{array}$ \\
\hline \multirow[t]{18}{*}{ Samsoun } & \multirow[t]{7}{*}{1888} & \multirow{7}{*}{$\begin{array}{c}\text { Porcelaine et } \\
\text { verrerie }\end{array}$} & Turquie & 39696 & \\
\hline & & & Belgique & 25375 & \\
\hline & & & France & 3500 & \\
\hline & & & Autriche & 2000 & \\
\hline & & & Grèce & 1000 & \\
\hline & & & Russie & 125 & \\
\hline & & & Total & 75756 & $248628 \mathrm{~kg}$ \\
\hline & \multirow[t]{4}{*}{1890} & \multirow[t]{4}{*}{ Faïence } & France & 3500 & $6000 \mathrm{~kg}$ \\
\hline & & & Autriche-Hongrie & 2360 & $4650 \mathrm{~kg}$ \\
\hline & & & Belgique & 2200 & $4350 \mathrm{~kg}$ \\
\hline & & & Total & 7610 & $15000 \mathrm{~kg}$ \\
\hline & \multirow[t]{4}{*}{1891} & \multirow[t]{4}{*}{ Faïence } & Belgique & 2500 & $5800 \mathrm{~kg}$ \\
\hline & & & France & 2500 & $5000 \mathrm{~kg}$ \\
\hline & & & Autriche-Hongrie & 2200 & $4500 \mathrm{~kg}$ \\
\hline & & & Total & 7200 & $15300 \mathrm{~kg}$ \\
\hline & \multirow[t]{3}{*}{1892} & \multirow[t]{3}{*}{ Faïence } & France & 2500 & $4000 \mathrm{~kg}$ \\
\hline & & & Autriche et Allemagne & 1600 & $3000 \mathrm{~kg}$ \\
\hline & & & Total & 4100 & $7000 \mathrm{~kg}$ \\
\hline \multirow[t]{13}{*}{ Trébizonde } & \multirow[t]{7}{*}{1888} & \multirow{7}{*}{$\begin{array}{c}\text { Porcelaine et } \\
\text { verrerie }\end{array}$} & Autriche et Allemagne & 39652 & \\
\hline & & & Angleterre & 9936 & \\
\hline & & & France & 3680 & \\
\hline & & & Suède et Belgique & 2760 & \\
\hline & & & Italie - Suisse & 1472 & \\
\hline & & & Russie & 607 & \\
\hline & & & Total & 58107 & $47300 \mathrm{~kg}$ \\
\hline & \multirow[t]{6}{*}{1890} & \multirow{6}{*}{$\begin{array}{c}\text { Porcelaine et } \\
\text { verrerie }\end{array}$} & Belgique et Suède & 39250 & 1520 colis \\
\hline & & & Autriche-Hongrie & 59700 & 1410 colis \\
\hline & & & France & 22510 & 347 colis \\
\hline & & & Angleterre & 8110 & 135 colis \\
\hline & & & Italie & 1800 & 30 colis \\
\hline & & & Total & 131370 & \\
\hline
\end{tabular}

${ }^{10}$ Dans un procès-verbal du conseil d'administration de la faïencerie de Nimy, établi le 16 août 1910 et concernant les requêtes de l'agent de la manufacture au Caire, il est encore question de «tonneaux d'emballage». E. BRUYERE, s.p., s.d. 


\begin{tabular}{|c|c|c|c|c|c|}
\hline Port d'arrivée & Date & Produits & Pays exportateurs & $\begin{array}{l}\text { Valeur en } \\
\text { franc }\end{array}$ & $\begin{array}{l}\text { Unités de } \\
\text { mesure }\end{array}$ \\
\hline & \multirow{7}{*}{1891} & \multirow{7}{*}{$\begin{array}{c}\text { Porcelaine et } \\
\text { verrerie }\end{array}$} & Autriche et Allemagne & 56600 & $141500 \mathrm{~kg}$ \\
\hline & & & France & 18120 & $30200 \mathrm{~kg}$ \\
\hline & & & Angleterre et colonies & 9000 & $15000 \mathrm{~kg}$ \\
\hline & & & $\begin{array}{l}\text { Suède, Danemark et } \\
\text { Belgique }\end{array}$ & 4200 & $7000 \mathrm{~kg}$ \\
\hline & & & Italie et Suisse & 3000 & $5000 \mathrm{~kg}$ \\
\hline & & & Turquie et Egypte & 1200 & $3000 \mathrm{~kg}$ \\
\hline & & & Total & 92120 & $\begin{array}{l}201700 \mathrm{~kg} \\
1931 \text { colis }\end{array}$ \\
\hline & \multirow[t]{7}{*}{1892} & \multirow{7}{*}{$\begin{array}{c}\text { Porcelaine et } \\
\text { verrerie }\end{array}$} & Autriche et Allemagne & 34240 & $85600 \mathrm{~kg}$ \\
\hline & & & France & 12000 & $20000 \mathrm{~kg}$ \\
\hline & & & Angleterre et Colonies & 6000 & $10000 \mathrm{~kg}$ \\
\hline & & & Suède et Belgique & 3600 & $6000 \mathrm{~kg}$ \\
\hline & & & Italie et Suisse & 2400 & $4000 \mathrm{~kg}$ \\
\hline & & & Turquie et Egypte & 1200 & $3000 \mathrm{~kg}$ \\
\hline & & & Total & 59440 & $\begin{array}{l}128600 \mathrm{~kg} \\
1220 \mathrm{colis}\end{array}$ \\
\hline \multirow{22}{*}{$\begin{array}{l}\text { Trébizonde à } \\
\text { destination de la } \\
\text { Perse }\end{array}$} & \multirow[t]{6}{*}{1888} & \multirow{6}{*}{$\begin{array}{c}\text { Porcelaine et } \\
\text { verrerie }\end{array}$} & Autriche et Allemagne & 70362 & \\
\hline & & & France & 33120 & \\
\hline & & & Angleterre & 14720 & \\
\hline & & & Italie et Suisse & 13800 & \\
\hline & & & Suède et Belgique & 5520 & \\
\hline & & & Total & 137522 & $130000 \mathrm{~kg}$ \\
\hline & \multirow[t]{4}{*}{1890} & \multirow[t]{4}{*}{ Porcelaine } & Autriche-Hongrie & 110840 & 1355 colis \\
\hline & & & Angleterre & 13200 & 165 colis \\
\hline & & & France & 18000 & 150 colis \\
\hline & & & Total & 142040 & \\
\hline & \multirow[t]{6}{*}{1891} & \multirow{6}{*}{$\begin{array}{c}\text { Porcelaine et } \\
\text { verrerie }\end{array}$} & Autriche et Allemagne & 104400 & $130500 \mathrm{~kg}$ \\
\hline & & & Angleterre & 20000 & $25000 \mathrm{~kg}$ \\
\hline & & & France & 24000 & $20000 \mathrm{~kg}$ \\
\hline & & & Italie et Suisse & 21600 & $18000 \mathrm{~kg}$ \\
\hline & & & Suède et Belgique & 7000 & $7000 \mathrm{~kg}$ \\
\hline & & & Total & 177000 & $\begin{array}{l}200500 \mathrm{~kg} \\
1960 \text { colis }\end{array}$ \\
\hline & \multirow[t]{6}{*}{1892} & \multirow{6}{*}{$\begin{array}{c}\text { Porcelaine et } \\
\text { verrerie }\end{array}$} & Autriche et Allemagne & 100000 & $125000 \mathrm{~kg}$ \\
\hline & & & Angleterre et Colonies & 18000 & $20000 \mathrm{~kg}$ \\
\hline & & & France & 21600 & $18000 \mathrm{~kg}$ \\
\hline & & & Italie et Suisse & 5000 & $5000 \mathrm{~kg}$ \\
\hline & & & Suède et Belgique & 2000 & $2000 \mathrm{~kg}$ \\
\hline & & & Total & 146600 & $\begin{array}{l}170000 \mathrm{~kg} \\
1650 \text { colis }\end{array}$ \\
\hline
\end{tabular}




\begin{tabular}{|c|c|c|c|c|c|}
\hline Port d'arrivée & Date & Produits & Pays exportateurs & $\begin{array}{c}\text { Valeur en } \\
\text { franc }\end{array}$ & $\begin{array}{l}\text { Unités de } \\
\text { mesure }\end{array}$ \\
\hline \multirow[t]{4}{*}{ Constantinople } & \multirow[t]{2}{*}{1890} & \multirow{2}{*}{ Marmites } & Grèce & 2374 & 3957 pièces \\
\hline & & & Turquie & 9411 & 15685 pièces \\
\hline & \multirow[t]{2}{*}{1891} & Porcelaine & I & & 1387 caisses \\
\hline & & Poterie & I & & $\begin{array}{l}4161 \text { caisses } \\
81682 \text { unités }\end{array}$ \\
\hline $\begin{array}{l}\text { Andrinople } \\
\text { (Edirne) }\end{array}$ & 1891 & $\begin{array}{c}\text { Faïence et } \\
\text { verrerie }\end{array}$ & Saxe & 7500 & \\
\hline \multirow[t]{4}{*}{ Thessalonique } & \multirow[t]{3}{*}{1890} & $\begin{array}{c}\text { Faïence } \\
\text { Porcelaine } \\
\text { importée par } \\
\text { bateau vapeur }\end{array}$ & $\begin{array}{l}1 \\
1\end{array}$ & & $\begin{array}{r}128700 \mathrm{~kg} \\
83200 \mathrm{~kg}\end{array}$ \\
\hline & & $\begin{array}{c}\text { Porcelaine } \\
\text { importée par } \\
\text { bateau à voile }\end{array}$ & I & & $312000 \mathrm{~kg}$ \\
\hline & & Poterie & & & $83200 \mathrm{~kg}$ \\
\hline & 1892 & $\begin{array}{c}\text { Porcelaine et } \\
\text { verrerie }\end{array}$ & I & 450000 & \\
\hline \multirow{5}{*}{$\begin{array}{l}\text { Dédéagatch } \\
\text { (Alexandroupolis) }\end{array}$} & \multirow[t]{2}{*}{1890} & \multirow{2}{*}{$\begin{array}{l}\text { Faïence et } \\
\text { verrerie }\end{array}$} & France & & $25000 \mathrm{~kg}$ \\
\hline & & & Autres & & $118000 \mathrm{~kg}$ \\
\hline & \multirow[t]{2}{*}{1891} & \multirow{2}{*}{$\begin{array}{c}\text { Faïence et } \\
\text { verrerie }\end{array}$} & France & & $9000 \mathrm{~kg}$ \\
\hline & & & Total & & $162000 \mathrm{~kg}$ \\
\hline & 1892 & $\begin{array}{c}\text { Faïence et } \\
\text { verrerie }\end{array}$ & I & & $13000 \mathrm{~kg}$ \\
\hline Monastir (Bitola) & 1891 & Poterie & 1 & 350000 & \\
\hline \multirow{16}{*}{$\begin{array}{l}\text { Candie } \\
\text { (Héraklion) }\end{array}$} & 1889 & Poterie & France & 16000 & \\
\hline & \multirow[t]{9}{*}{1890} & \multirow{9}{*}{$\begin{array}{c}\text { Porcelaine et } \\
\text { verrerie }\end{array}$} & Autriche & 85000 & \\
\hline & & & Egypte & 30000 & \\
\hline & & & Angleterre & 14000 & \\
\hline & & & Italie & 7000 & \\
\hline & & & Turquie & 4000 & \\
\hline & & & France & 2000 & \\
\hline & & & Grèce & 2000 & \\
\hline & & & Divers & 3000 & \\
\hline & & & Total & 115000 & \\
\hline & 1891 & Poterie & France & 65000 & \\
\hline & \multirow[t]{5}{*}{1892} & \multirow{5}{*}{$\begin{array}{c}\text { Porcelaine et } \\
\text { verrerie }\end{array}$} & France & & 70 colis \\
\hline & & & Angleterre & & 40 colis \\
\hline & & & Allemagne & & 40 colis \\
\hline & & & Autriche-Hongrie & & 25 colis \\
\hline & & & Turquie & & 15 colis \\
\hline
\end{tabular}




\begin{tabular}{|c|c|c|c|c|c|}
\hline Port d'arrivée & Date & Produits & Pays exportateurs & $\begin{array}{c}\text { Valeur en } \\
\text { franc }\end{array}$ & $\begin{array}{l}\text { Unités de } \\
\text { mesure }\end{array}$ \\
\hline & & \multirow[t]{4}{*}{ Poterie } & France & & 4700 pièces \\
\hline & & & Italie & & 1500 pièces \\
\hline & & & Turquie & & 1300 pièces \\
\hline & & & Grèce & & 1200 pièces \\
\hline & & Porcelaine & Grèce & & 6 tonneaux \\
\hline \multirow[t]{2}{*}{$\begin{array}{l}\text { Aïvaly } \\
\text { (Ayvalık) }\end{array}$} & $\begin{array}{c}1892 \\
\text { et }\end{array}$ & Jarres à huile & I & & 216 colis \\
\hline & 1894 & Poterie & l & & 41609 colis \\
\hline \multirow{10}{*}{$\begin{array}{l}\text { Smyrne } \\
\text { (Izmir) }\end{array}$} & \multirow[t]{9}{*}{1891} & \multirow{4}{*}{$\begin{array}{l}\text { Porcelaine et } \\
\text { cristaux }\end{array}$} & France & 119500 & \\
\hline & & & Amérique & 23500 & \\
\hline & & & Angleterre & 15500 & \\
\hline & & & Total & 158500 & $317000 \mathrm{~kg}$ \\
\hline & & \multirow[t]{5}{*}{ Terrailles } & France & 149760 & \\
\hline & & & Turquie & 136020 & \\
\hline & & & Autriche & 9180 & \\
\hline & & & Grèce & 7080 & \\
\hline & & & Total & 302640 & $5044000 \mathrm{~kg}$ \\
\hline & 1893 & $\begin{array}{c}\text { Faïence et } \\
\text { verrerie }\end{array}$ & Constantinople & 299000 & \\
\hline \multirow[t]{2}{*}{ Samos } & 1890 & $\begin{array}{l}\text { Poterie de } \\
\text { Marseille et } \\
\text { de Savone }\end{array}$ & I & 1 & \\
\hline & 1892 & Poterie & Turquie, Italie, France & $\begin{array}{r}46376 \\
\text { piastres }\end{array}$ & \\
\hline Rhodes & 1891 & Marmites & France & 1500 & \\
\hline \multirow{10}{*}{$\begin{array}{l}\text { Alexandrette } \\
\text { (Iskenderun) }\end{array}$} & \multirow[t]{7}{*}{1890} & \multirow{7}{*}{$\begin{array}{c}\text { Porcelaine et } \\
\text { verrerie }\end{array}$} & France & 157560 & \\
\hline & & & Autriche & 58670 & \\
\hline & & & Turquie & 35760 & \\
\hline & & & Egypte & 5770 & \\
\hline & & & Angleterre & 2680 & \\
\hline & & & Autres pays & 9500 & \\
\hline & & & Total & 269940 & $219100 \mathrm{~kg}$ \\
\hline & \multirow[t]{3}{*}{1892} & \multirow{2}{*}{$\begin{array}{l}\text { Faïence et } \\
\text { porcelaine }\end{array}$} & France & 42117 & $35098 \mathrm{~kg}$ \\
\hline & & & Autriche & 5831 & $7289 \mathrm{~kg}$ \\
\hline & & Faïence & Belgique & 7529 & $7529 \mathrm{~kg}$ \\
\hline
\end{tabular}

TABLEAU 2. Importations de vaisselle dans l'Empire, entre 1870 et 1893, d'après $V$. Cuinet et les comptes rendus de la Chambre de commerce d'Istanbul 
Lors de l'exposition universelle de 1878, V. de Luynes dressait, à partir du Tableau général du commerce de la France publié par les soins de l'administration des douanes, un inventaire des exportations des produits céramiques (tableau 3). Ces données confirment l'expédition de poteries de terre commune et de faïences vers la Turquie et la Grèce entre 1867 et $1878^{11}$.

\begin{tabular}{|l|l|r|r|}
\hline \multirow{2}{*}{$\begin{array}{c}\text { Pays } \\
\text { importateurs }\end{array}$} & \multicolumn{1}{|c|}{ Produits } & $\begin{array}{c}\text { Quantités en kg } \\
\text { sur toute la } \\
\text { période }\end{array}$ & \multicolumn{1}{c|}{$\begin{array}{c}\text { Moyenne } \\
\text { annuelle }\end{array}$} \\
\hline \multirow{2}{*}{ Turquie } & Poteries cuite en dégourdi & & \multicolumn{1}{c|}{ 12 } \\
\cline { 2 - 4 } & Porcelaine commune & 4256162 & 354680 \\
\cline { 2 - 4 } & Faïence & 1098996 & 91583 \\
\cline { 2 - 4 } & Porcelaine fine & 920323 & 76693 \\
\hline Grèce & Poteries cuites en dégourdi & 1114640 & 32829 \\
\hline
\end{tabular}

TABLEAU 3. Exportations françaises des produits céramiques de 1867 à 1878 selon $V$. de Luynes

A. Talandier, dans son Rapport sur l'industrie céramique en France et en Angleterre publié en 1873, rapporte qu' «On sait généralement que parmi les nations chez lesquelles le bel art industriel de la céramique a pris un grand développement, l'Angleterre est aujourd'hui la seule qui puisse faire à la France une concurrence sérieuse; mais on ne sait pas assez de quels prodigieux avantages moraux et matériels jouit l'Angleterre, combien sa puissance de production est incalculable, à quel point la terre entière est ouverte à son commerce et avide de recevoir ses produits ${ }^{13}$. Les chiffres qu'il donne rendent bien compte de la position de

11 V. de LuYNES, «Groupe III. - Classe 20. Rapport sur la céramique» dans Exposition universelle de 1878 à Paris. Rapports du jury international, Paris, 1882, p. 9, 10. À titre de comparaison, voici les quantités maximales et minimales des achats par type et par pays : - poteries cuites en dégourdi, $10803117 \mathrm{~kg}$ envoyés en Italie, $638994 \mathrm{~kg}$ au Brésil, et $4275692 \mathrm{~kg}$ expédiés en Egypte; — faïences, $4114107 \mathrm{~kg}$ envoyés en Algérie et $425526 \mathrm{~kg}$ en Guadeloupe; - porcelaine commune, $14998743 \mathrm{~kg}$ envoyés sur la côte est des Etats-Unis, c'est l'Egypte qui en achète le moins avec 496676 kg; - porcelaine fine, $5134569 \mathrm{~kg}$ envoyés en Angleterre, $141862 \mathrm{~kg}$ expédiés vers l'Egypte et $125140 \mathrm{~kg}$ en Uruguay.

${ }_{12}$ Terme s'appliquant à une cuisson à basses températures entre 400 et $700^{\circ}$. Les poteries ont perdu leur plasticité mais restent poreuses. Etant donné le contexte, ce terme désigne sans doute les céramiques communes.

13 A. TALANDIER, Rapport sur l'industrie céramique en France et en Angleterre, 1873, p. $409,415,416$. 
quasi-monopole occupée par la Grande-Bretagne. Ainsi en 1861, l'Angleterre exportait pour $26763250 \mathrm{f}$. de faïences et de porcelaines, soit pour une valeur presque quatre fois plus élevée que ce que la France envoyait à l'étranger (7 023037 f.). En 1869, les exportations anglaises avaient une valeur cinq fois plus élevées que les françaises : 44252750 f. contre 7577219 f. La France a atteint son maximum en 1864, en exportant de la vaisselle pour 9967116 f. L'exploitation de ces quelques sources montre qu'un commerce organisé de vaisselle existait entre l'Europe et l'Empire ottoman. Des approvisionnements réguliers et conséquents se faisaient par les grands ports de mer Noire et d'Egée. Dans les boutiques et sur les marchés de Roumélie et d'Anatolie, les commerçants proposaient donc à la vente des produits européens qui ne trouvaient localement aucun rival.

\section{LES PRODUCTIONS EUROPÉENNES COMMERCIALISÉES}

DANS L'EMPIRE

Les importations de vaisselle dans l'Empire ottoman sont désignées, dans les textes commerciaux, par les termes faïence, porcelaine, poterie, terraille et jarre. En l'absence de précisions supplémentaires, il est difficile de déterminer les types de production et d'identifier les manufactures dont ils proviennent, d'autant plus qu'à une même appellation correspondent parfois plusieurs produits. Pourtant, à partir des découvertes de terrain, il est possible de reconnaître certains objets, de révéler leurs origines et de préciser leurs caractéristiques techniques et stylistiques. En croisant les sources écrites avec les découvertes archéologiques et des enquêtes chez les antiquaires, un premier inventaire des produits de terre importés sur une partie des territoires de la Sublime Porte peut être proposé.

\section{Poterie et autres terrailles}

D'après les statistiques établies par V. Cuinet, Monastir, Rhodes et Aïvaly ne recevaient, à la fin du XIX ${ }^{\mathrm{e}}$ siècle, que des poteries tandis que marmites, terrailles et jarres alimentaient le commerce de Smyrne, de Candie, de Thessalonique aux côtés d'autres objets de terre. Samos, qui était connue pour sa production de céramiques qu'elle exportait, recevait cependant des poteries de Marseille et de Savone ${ }^{14}$. Les marchés de

14 V. CuINET, vol. III, Istanbul, Isis Edition, 2001, p. 113. 
Constantinople étaient aussi alimentés, en 1890, par 15000 marmites venues d'Anatolie et 3957 fabriquées en Grèce. En 1891, la Grèce exportait 97000 pièces de poteries communes et la Turquie, 1342760 pièces ${ }^{15}$. Ces mêmes produits anatoliens et grecs étaient aussi livrés, en quantités moins importantes, à Candie, à Samos et à Smyrne. Les autres pays fournisseurs de terrailles étaient l'Italie, l'Autriche et la France. À Chypre, des rapports consulaires, établis au $\mathrm{XIX}^{\mathrm{e}}$ siècle, signalaient aussi des importations de poterie et de vaisselle de terre originaires de France, d'Autriche, d'Italie et de Turquie, livrés dans les ports de Larnaka et de Limassol ${ }^{16}$. Et, comme le signalait A. Boué, en 1840, pour la Turquie d'Europe «La poterie grossière vient de Hongrie par Semlin ou des Etats autrichiens, et surtout de la Bohême par Trieste, Scutari, Douratzo ou Salonique; une énorme quantité de cruches noires à eau ou à vin proviennent des environs de Mohatsch en Hongrie ${ }^{17}$. Enfin, selon le savant X. Heuschling, l'Angleterre envoyait également vers l'Empire des $«$ poteries de terre ${ }^{18}$. Une partie de ces terrailles peut être identifiée.

Les jarres, chargées à Marseille et débarquées à Sidon en 1780 et 1781, à Tripoli en 1812 et à Beyrouth en 1825 et 1826, comme en attestent les documents publiés par M. Milwright ${ }^{19}$, provenaient sans doute des ateliers de Biot, un village des Alpes-Maritimes spécialisé, dès le XVIII ${ }^{\mathrm{e}}$ siècle, dans la fabrication de gros contenants étanches bien adaptés à la conservation de l'huile ${ }^{20}$. Dans les différents pays du bassin méditerranéen, les jarres de Biot servaient plus particulièrement pour la préparation des saumures, pour la conservation des engrais, des céréales, des olives, des fruits ou des légumes secs et, dans la Marine royale française, les intendants préféraient ces jarres aux barils pour contenir l'eau destinée à la consommation des officiers à bord. Les jarres de Biot «capitale méridionale de la jarre» — entre 1828 et 1830 , la production

15 Chambre de commerce française de Constantinople, Compte-rendu des travaux, année 1891, Constantinople, 1893, p. 285.

16 I. Ionas, Traditional Pottery and Potters in Cyprus. The Disappearance of an Ancient Craft Industry in the 19th and 20th Centuries, Birmingham Byzantine and Ottoman Monographs, vol. 6, Ashgate, 2000, p. 81, note 35.

17 A. Boué, 1840 , tome III, p. 165-166.

18 X. Heuschling, 1860, p. 183, 186.

19 M. Milwright, 2008, p. 121-152

20 H. Amouric, L. Argueyrolles, L. Vallauri, Biot. Jarres, terrailles et fontaines, $X V I^{e}-X X^{e}$ siècles, Vence, 2006; H. Amouric, L. VAllauri, Voyages et métamorphoses de la jarre, Aubagne, 2005, p. 73-90. 
était estimée à 84000 pièces annuelles - embarquées dans le port d'Antibes, transitaient par Marseille d'où elles étaient distribuées dans toute la Méditerranée mais aussi au Portugal, en Angleterre, en Suisse, «aux isles de l'Amérique», au Pérou, au Sénégal et à Madagascar. Les sorties du port de Marseille indiquent qu'entre 1724 et 1780, 31182 jarres de Biot furent expédiées vers toutes ces destinations et, parmi elles, 1395 furent envoyées au Levant. Ces gros contenants étaient parfois importés dans des régions qui étaient elles mêmes productrices de jarres comme à Chypre. Sur cette île, les ateliers ruraux, tels que ceux de Kornos et de Phini, fabriquaient de grosses jarres destinées principalement à la conservation du vin; ces pitharia avaient des parois extrêmement poreuses et ne convenaient donc pas pour conserver l'huile d'olive produite en grande quantité au nord de l'île, dans la région de Kyrénia. C'est pourquoi les paysans leur préféraient les jarres importées de Crète ${ }^{21}$ et de Messénie ${ }^{22}$ par le port de Kyrénia et celles, couvertes d'une épaisse glaçure jaune, venues de France et appelées localement tjarra ${ }^{23}$. Ces jarres glaçurées, d'après divers témoignages, arrivaient vides d'Italie et étaient stockées en grand nombre dans les entrepôts de Kyrénia. On les retrouve aujourd'hui dans ce port, au détour des rues, remployées en cache-pot ainsi qu'à Dhali et à Larnaka ${ }^{24}$ (Pl. 1: 1). Au Levant, c'étaient pour leur solidité et pour leur glaçure que les «jarres de France» étaient choisies au dépend des fabrications locales ainsi que le rapporte le consul de France au début du XIX ${ }^{\mathrm{e}}$ siècle: «comme depuis quelques années nos bâtiments n'apportent plus de ces jarres, les Tripolins ont recours à celles de Lattaquié qui ne sont pas vernillées et se brisent facilement ${ }^{25}$. Enfin des jarres de Biot sont aussi attestées dans le nord-ouest du Péloponnèse, à Naupakte et dans les îles ioniennes, notamment à Ithaque ${ }^{26}$. À Istanbul, il n'est pas rare d'en trouver chez les antiquaires aux côtés de jarres crétoises (Pl. 1:2). Et si les jarres à huile mentionnées dans les entrées du port d'Aïvaly en 1892 (tableau 2)

${ }^{21}$ Sur les jarres fabriquées en Crète voir notamment $\mathrm{Ph}$. Gouin, Ch. VogT, «Les pithoi de Margaritès (Crète)», Techniques et Culture 38, La céruse, mars 2002, p. 1-20.

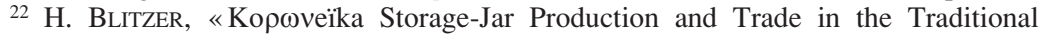
Aegean », Hesperia 59, 1990, p. 675-711.

${ }^{23}$ I. IONAS, 2000, p. 61.

24 V. FrançoIs, L. VALLAURI, «Production et consommation de céramiques à Potamia (Chypre) de l'époque franque à l'époque ottomane», $B C H$ 125, 2, 2001, p. 545.

25 A. IsmaIL, Documents diplomatiques et consulaires relatifs à l'histoire du Liban: et des pays du Proche-Orient du XVII e siècle à nos jours, vol. IV, Beyrouth, 1976, p. 386.

${ }^{26}$ H. BlitZer, 1990, pl. 112 b. 
ont pu venir de Biot, celles qui ont été repérées jusqu'à présent dans le district d'Ayvalık sont originaires des ateliers de Koroni en Messénie, un village célèbre pour sa fabrication de grosses jarres adaptées à la conservation de l'huile d'olive ${ }^{27}$. Il ne faudrait pas croire que les Turcs se contentaient d'importer des jarres, ils en fabriquaient aussi. Ainsi V. Cuinet signale, dans le vilayet (province) de Sivas, l'existence de six ateliers employant 200 ouvriers qui fabriquaient, outre de la vaisselle commune pour les usages locaux, des jarres. De la même façon, dans le sandjak (département) de Tokat, les ateliers produisaient de grandes jarres dans lesquelles les paysans conservaient le vin. Des fours spécifiques étaient construits pour leur cuisson ${ }^{28}$. On trouve aujourd'hui, dans les salles des ventes en Turquie, de petites jarres de Tokat, à pâte rouge, à panse balustre avec quatre anses, glaçurées au plomb en vert, hautes de $64 \mathrm{~cm}$ pour un diamètre à l'ouverture de $18 \mathrm{~cm}$.

Les documents évoquent aussi des «poteries de Marseille» importées à Samos et des «marmites de France» transportées à Rhodes (tableau 2). Ces céramiques culinaires peuvent être identifiées avec des marmites de Vallauris qui, comme les jarres de Biot, ont été commercialisées à très grande échelle. Leur prix très bas contribuait à leur succès. Au $\mathrm{XVIII}^{\mathrm{e}}$ siècle, à Vallauris, un village des Alpes-Maritimes, une trentaine de fabriques produisaient principalement des marmites. Ces céramiques culinaires étaient fabriquées avec une argile réfractaire très résistante aux chocs thermiques et donc bien adaptée à leur fonction. Ces terrailles de diverses tailles, glaçurées au plomb à l'intérieur, ont un bord caréné et deux anses marquées au pouce. Elles étaient transportées par bateaux d'Antibes à Marseille où elles alimentaient non seulement le commerce local mais aussi le commerce des exportations. De là elles étaient expédiées en Italie, en Espagne, dans les îles françaises d'Amérique, en Guyane et au Canada ${ }^{29}$. Au Proche-Orient, on en trouve à Chypre, exposées dans des musées villageois ou chez l'habitant et, en contexte d'utilisation, dans la région de Potamia $^{30}$ (Pl. 1: 4). Il semble qu'elles ont servi de modèles aux potiers locaux ${ }^{31}$. En effet, selon divers témoignages, les marmites glaçurées employées à Chypre au XIX ${ }^{\mathrm{e}}$ siècle

27 Ibidem, p. 704, pl. 112 g.

28 V. CUINET, vol VI., p. 307 et 359.

${ }^{29}$ H. Amouric, Fl. Richez, L. Vallauri, Vingt mille pots sous les mers, Aix-en-Provence, 1999, p. 131-135.

${ }^{30}$ V. François, L. VAllauri, 2001, p. 545.

${ }^{31}$ I. IONAS, 2000 , p. $69-70$, fig. 2.50 et 51. 
étaient importées des îles de l'Egée et de France. Au début du XX siècle, l'administration anglaise interdit ces importations, encourageant les artisans chypriotes à fabriquer des marmites à glaçure, ce qu'avaient déjà tenté les potiers de Kornos et des Troodos. C'est sans doute pour cette raison que certaines marmites chypriotes ressemblent en tous points aux céramiques culinaires de Vallauris. En 1891, Chypre exportait 145330 pièces de poterie commune ${ }^{32}$. Enfin aujourd'hui, des marmites de Vallauris sont proposées à la clientèle des antiquaires stambouliotes (Pl. 1: 3) et les découvertes de Siphnos montrent que ces terrailles étaient également distribuées dans les îles de l'Egée ${ }^{33}$.

Les ateliers français n'étaient pas les seuls fournisseurs de poteries, les fabriques d'Italie vendaient aussi certaines de leurs productions à l'export, notamment par le port de Savone (tableau 2). Au XVIII ${ }^{\mathrm{e}}$ siècle, les importations italiennes étaient connues, dans les îles ioniennes et dans la région de Naupakte, sous le nom de $\Lambda 1 \beta o \rho v o \delta \varepsilon-$ $\sigma \imath \kappa \alpha$ ou vaisselle de Livourne - les petites jarres de stockage trouvées au sud de la Messénie étaient d'ailleurs appelées $\Lambda \imath \beta \eta^{34}$. Ce port, aux $\mathrm{XVIII}^{\mathrm{e}}$ et $\mathrm{XIX}^{\mathrm{e}}$ siècles, faisait en effet un commerce important avec la Grèce. Pour autant, nous ne savons pas où étaient produites ces céramiques communes. Dans ces conditions, il est impossible de dire d'où provenaient exactement les poteries italiennes vendues à Candie en 1892 (tableau 2). En revanche, les jarres glaçurées au plomb, retrouvées en Messénie, ont été fabriquées dans les ateliers des Pouilles et de Sicile.

La Hongrie est également citée parmi les pays exportateurs, elle fournissait des cruches noires à eau ou à vin. Les cruches et pichets cuits en atmosphère réductrice étaient en effet caractéristiques des productions balkaniques et hongroises des $\mathrm{XVI}^{\mathrm{e}}-\mathrm{XVII}{ }^{\mathrm{e}}$ siècles $^{35}$ et étaient encore fabriqués au XIX ${ }^{\mathrm{e}}$. Cependant l'archéologie n'a permis d'identifier aucune de ces productions en Méditerranée orientale.

32 Chambre de commerce française de Constantinople, Compte rendu des travaux, année 1891, Constantinople, 1893, p. 285.

33 J. Vroom, Byzantine to Modern Pottery in the Aegean, Parnassus Press, 2005, p. 192, fig. 6.2 .

${ }^{34}$ H. BLITZER, 1990, p. 705, note 26.

35 G. Tomka, «Finjans, Pipes, Grey Jugs» in I. Gerelyes, G. Kovács (eds.), Archaeology of the Ottoman Period in Hungary, Budapest, 2003, p. 313-314; V. BIKIĆ, Gradska keramika Beograda (16-17. vek.) (Belgrade Ceramics in the $16^{\text {th }}-17^{\text {th }}$ Century), Belgrade, 2003, p. 148, fig. 32. 


\section{Faïences}

Comme en attestent les rapports consulaires et les documents statistiques, les faïences constituaient une part importante des exportations européennes de vaisselle vers le Levant dès le XVIII ${ }^{\mathrm{e}}$ siècle $^{36}$ et, encore à la fin du XIX ${ }^{\mathrm{e}}$, vers la Roumélie et l'Anatolie. Elles provenaient de France, par Marseille — en 1886, la France exportait pour 3970929 f. de faïences, en 1887 pour $4659550 \mathrm{f}$. et en 1888 pour $5097739 \mathrm{f}$. L'Egypte, la Turquie et les pays du protectorat faisaient partie de ses marchés ${ }^{37}$. Les autres pays fournisseurs étaient la Belgique, l'AutricheHongrie, l'Italie et l'Allemagne. Selon A. Talandier, l'Angleterre inondait tous les marchés avec ses faïences et ses poteries communes de terre et de grès. En 1870, les plus grosses exportations de faïence anglaise envoyées en Méditerranée orientale étaient destinées, par ordre décroissant, à la Turquie d'Europe (560 275 f.), à l'Egypte (256 600 f.), à la Syrie et la Palestine (150 425 f.), à la Grèce (143 350 f.). Sur les côtes de mer Noire, Samsoun recevait régulièrement des quantités moyennes de faïences alors que Trébizonde n'en recevait aucune. Dans le port de Thessalonique en revanche ce sont d'importants volumes qui arrivaient. Il est difficile d'estimer la part relative des autres destinations turques car la faïence est associée, dans les archives, aux verreries et parfois aux porcelaines. Chypre était, depuis la fin du XVIII ${ }^{e}$ siècle, un port de transit pour ces marchandises sur la route maritime reliant Marseille aux ports du Levant ${ }^{38}$. Et il est probable qu'une partie des cargaisons de faïences ait été déchargée et vendue dans l'île.

Le terme «faïence» recoupe, pour les $\mathrm{XVIII}^{\mathrm{e}}$ et $\mathrm{XIX}^{\mathrm{e}}$ siècles, deux fabrications distinctes qui sont d'une part des poteries à pâte argileuse colorée, perméable à l'eau, couvertes d'une glaçure opaque blanche obtenue grâce à de l'oxyde d'étain mélangé à une solution alcalinoplombifère et, d'autre part, des «faïences fines » à pâte opaque, blanche ou ivoire, à texture dense et sonore, couvertes d'une glaçure transparente

36 Voir les sorties du port de Marseille à destination du Levant publiées par H. AmOURIC, La faïence de Marseille au XVIII e siècle. La manufacture de la Veuve Perrin, Musées de Marseille / Editions Agep, 1990, p. 82-93 et les rapports consulaires français au Levant publiés par M. Milwright dans ce volume.

${ }^{37}$ Les autres pays importateurs sont l'Espagne, la Suisse, le Portugal, l'Italie, certaines colonies françaises, le Brésil, l'Argentine et les Etats-Unis. V. de LyunEs 1882, p. 50; M.J. LoEBNITZ, «Classe 20 Céramique, Rapport du jury international», dans Ministère du commerce, de l'industrie et des colonies. Exposition universelle internationale de 1889 à Paris, Paris, 1891, p. 226.

${ }^{38}$ M. Milwright, 2008, p. 121-152. 
alcalino-plombifère. Si les premières étaient fabriquées depuis le Moyen Age, les secondes virent le jour en Angleterre, dans la région du Staffordshire, au cours du second tiers du XVIII ${ }^{\mathrm{e}}$ siècle et, en France, au milieu de ce même siècle. D’après les découvertes archéologiques, les céramiques émaillées, parfois qualifiées de terrailles eut égard à leur qualité grossière, étaient plutôt caractéristiques des exportations du $\mathrm{XVIII}^{\mathrm{e}}$ siècle et du début du $\mathrm{XIX}^{\mathrm{e}}$ tandis que les «faïences fines » dominaient le marché par la suite.

\section{«Faïences » ou céramiques émaillées}

Les faïences, évoquées dans les documents datés de la deuxième moitié du XVIII ${ }^{\mathrm{e}}$ siècle, embarquées sur des navires ancrés à Marseille, étaient sans doute issues, pour une partie au moins, des fabriques provençales de Marseille, Moustier, Varages ou le Castellet comme en témoignent quelques découvertes archéologiques ${ }^{39}$.

\begin{tabular}{|c|c|}
\hline Date & Poids en livre \\
\hline 1749 & 12300 \\
\hline 1750 & 32625 \\
\hline 1751 & 43660 \\
\hline 1752 & 25404 \\
\hline 1753 & 28657 \\
\hline 1754 & 29420 \\
\hline 1755 & 42580 \\
\hline 1756 & 12120 \\
\hline 1757 & 26900 \\
\hline 1758 & 23090 \\
\hline 1759 & 17465 \\
\hline
\end{tabular}

TABleau 4. Sorties de faïences du port de Marseille à destination du Levant entre 1749 et 1759 (d'après H. Amouric, 1990)

Ainsi, ce sont des faïenceries de Moustier (Alpes-de-Haute-Provence) que proviennent le bord d'un grand plat à marli orné d'un décor végétal peint en camaïeu de jaune jonquille trouvé à $\operatorname{Damas}^{40}$ (Pl. 1: 5), une assiette mise au jour à Saraçhane Camii à Istanbul et attribuée à l'Ita-

39 H. AmOURIC, 1990, p. 82-93.

$40 \mathrm{~V}$. FRAnÇOIS, Céramiques d'époques mamelouke et ottomane à la citadelle de Damas, 2008. 
$\operatorname{lie}^{41}$, et un fragment récemment trouvé à Fostat en Egypte ${ }^{42}$. Ces objets à l'émail blanc, lisse et brillant, appliqué sur une pâte argileuse, rosée, fine et légère, sont caractéristiques de la production de vaisselle polychrome à grand feu adoptée à Moustier vers $1740^{43}$. Un unique représentant des faïenceries de Varages dans le Haut-Var est apparu dans les fouilles de la citadelle de $\operatorname{Damas}^{44}$ (Pl. 1: 6). Il s'agit d'un bord de coupe, à pâte fine de couleur rose jaune, à décor de chaînons, peint en camaïeu bleu sur un émail blanc gras et onctueux ${ }^{45}$.

La «fayance brune», exportée par le port de Marseille, faisait partie des marchandises commandées par les Levantins comme le rapporte, en septembre 1814, le consul de France à Seyde (Sidon) ${ }^{46}$. Ces «fayances brunes » sont en fait des céramiques «à taches noires » réalisées dans les ateliers d'Albisola, dans la région de Gênes, qui produisaient en masse - en 1798, quarante-huit ateliers fabriquaient vingt-quatre millions de pièces ${ }^{47}$. Dans les inventaires mobiliers du sud de la France, cette production était aussi appelée «fayance brune dite de Genes », «fayance de Genes», «terre ou terraille de gene ${ }^{48}$. Bien que n'étant pas une faïence, cette céramique était apparemment considérée comme telle alors qu'il s'agit d'une poterie à glaçure plombifère de couleur café ornée de lignes ondulées tracées en noir. La «fayence brune», grossière, était parfois assimilée à des terrailles. Très bon marché, elle était largement diffusée dans toute la Méditerranée et jusqu'en Amérique du Nord ${ }^{49}$.

41 J. HAYES, 1992, p. 265, pl. 44: a.

42 Ce tesson apparaît sur le site Internet de l'University College de Londres, sous le $\mathrm{n}^{\circ}$ 25336. Merci à Lucy Vallauri de me l'avoir signalé.

43 L. Julien, L'art de la faïence de Moustiers, XVII ${ }^{e}-X V I I I^{e}-X I X^{e}$ siècles, Edisud, Aixen-Provence, 1991, p. 97 n 85 , p. 132, nº133.

44 Les ateliers, en activité dès 1695, se sont multipliés en 1725. P. BERTRAND, Faïences et faïenceries de Varages, Toulon, 1983, p. 89; La céramique, l'archéologue et le potier. Etudes de céramiques à Aubagne et en Provence du XVI au XIXe siècle, Aubagne, 1991, p. 76-82.

45 Pour un décor semblable voir D. Foy, F. Richez, L. VAllauri, «Les céramiques en usage dans l'atelier de verrier de Roquefeuille (Pourrières, Var)», Midi Médiéval IV, 1986, p. 145 , fig. $10: 5$, p. 146 , fig. 12 .

46 A. Ismail, Documents diplomatiques et consulaires relatifs à l'histoire $d u$ Liban: et des pays du Proche-Orient du XVII e siècle à nos jours, vol. III, Beyrouth, 1976, p. 115.

${ }^{47}$ H. BLAKE, «Pottery Exported from Northwest Italy between 1450 and 1830: Savona, Albisola, Genoa, Pisa and Montelupo», in G. BARKER, R. Hodges (eds.), Archaeology and Italian Society, Prehistoric, Roman and Medieval Studies, Oxford, BAR, 1981, p. 99-124.

48 H. Amouric, Fl. Richez, L. Vallauri, 1999, p. 119-125.

49 L. Long, F. RicheZ, «L'épave Grand-Congloué 4 », dans Un Goût d'Italie, Céramiques et céramistes italiens en Provence du Moyen Age au XXe siècle, Narration, 
Cependant, les trouvailles de céramiques «à tâches noires » sur les territoires de l'Empire ottoman sont exceptionnelles. Des exemplaires de cette production sont attestés à Beyrouth ${ }^{50}$ et, à Damas, où une petite jatte à lèvre éversée, épaissie à l'extérieur, et une grande assiette à marli oblique souligné par un ressaut, sont apparues dans les fouilles de la citadelle (Pl. 2: 1). À Saint-Jean d'Acre, l'exploration archéologique de maisons ottomanes a livré une grande assiette à bord éversé d'Albisola ${ }^{51}$. À Chypre, plusieurs plats et assiettes ont été mis au jour sur le site de Kouklia, un village à vocation agricole, et des fragments ont été trouvés à Potamia ${ }^{52}$. Une assiette entière est insérée dans une voûte de l'église de la Panagia Chriseleousa à Empa ${ }^{53}$.

La «fayance brune » était souvent commercialisée avec une autre production ligure bon marché, les «terrailles de Rome» ou «fayances de Rome», des assiettes et des grands plats à pâte rouge, épais, couverts d'un émail blanc souvent fragile. Cette vaisselle blanche unie était fréquemment qualifiée dans les textes de « grossière», «lourde et peu résistante ${ }^{54}$. Elle pourrait, comme la céramique «à taches noire » d'Albisola, être désignée dans les documents portuaires de terraille et non de faïence. Jusqu'à présent cette production de la région de Gênes n'a été reconnue qu'à Chypre, sur le site de Potamia ${ }^{55}$.

D'autres productions italiennes du XVIII ${ }^{\mathrm{e}}$ siècle sont présentes en Méditerranée orientale et, parmi elles, des faïences polychromes toscanes à décor de spirale verdi des ateliers de Pise. À Chypre encore, plusieurs fragments d'assiettes de ce type ont été recueillis à Potamia tandis que, dans l'église de la Panagia Kanakaria à Lythrankomi, une assiette entière est encore en place dans la voûte du narthex. Elle y a probablement été placée en 1779 durant les travaux de restauration de la voûte. Dans cette église, on trouve aussi des faïences ligures peintes en bleu et

Aubagne, 1993, p. 93-95; M. Moussette, «La poterie d'Albisola en Amérique du Nord», ibidem, p. 98-99.

50 Communication personnelle de J.W. Hayes à M.L. von Warburg.

51 G. Edelstein, M. Avissar, «A Sounding in Old Acre», 'Atiqot, XXXI, 1997, p. 131, fig. 1: 11, p. 132 .

52 M.L. Von Wartburg, «Types of Imported Table Ware at Kouklia in the Ottoman Period », RDAC 2001, p. 379, 380, fig. 8: 63-65, fig. 10: 30; V. FrANÇOIS, L. VALLAURI, 2001, p. 545.

53 I. HadjIKYRIakos, «La Decorazione Ceramica degli Interni Nelle Chiese di Cipro », RDAC 2006, p. 389-405.

54 H. Amouric, Fl. Richez, L. Vallauri, 1999, p. 119-124.

55 V. François, L. Vallauri, 2001, p. 545. 
jaune a prezzemolo e ucceli ${ }^{56}$ de même que dans les fouilles de Kouk$\mathrm{lia}^{57}$. Un tesson de spirale verdi est également exposé au musée de Larnaka tandis qu'à La Canée, en Crète, les fouilles ouvertes dans le quartier de Kastelli, ont mis en évidence plusieurs fragments de cette nature ${ }^{58}$.

Au XIX ${ }^{e}$ siècle, l'Italie exportait également vers les îles de l'Egée, en Grèce continentale (en Béotie et en Etolie), dans les Balkans et en Anatolie (sur le site de Myra en Lycie et à Dortyöl dans le Hatay) et même dans la province de Châm (à Damas) (Pl. 2: 2) des faïences assez rustiques fabriquées dans les ateliers de Grottaglie dans les Pouilles ${ }^{59}$. Il s'agit de pichets à embouchure trilobée, d'amphorettes et d'assiettes, ornés de grecques, de guirlandes fleuries, d'oiseaux, de personnages ou d'architectures, peints en bleu, vert et jaune sur émail ${ }^{60}$. Compte tenu de la qualité assez grossière de ces faïences, il n'est pas exclu qu'elles aient été enregistrées, dans les documents commerciaux, sous l'appellation poterie ou terraille.

\section{«Faïences fines 》}

En France, les principales manufactures de faïences fines étaient implantées à Sarreguemines (Moselle), à Creil-Montereau (Seine), à Gien (Loiret), à Bordeaux (Gironde) et à Choisy-le-Roi (Val-de-Marne). Une vingtaine de petites fabriques étaient par ailleurs disséminées sur tout le territoire. Ces entreprises exportaient une part plus ou moins grande de leur production vers l'Orient. À la manufacture de Sarreguemines, créée en 1790 et qui connut un développement constant au cours du XIX ${ }^{\mathrm{e}}$ siècle avec ses succursales de Digoin en Bourgogne et de Vitryle-François en Champagne, les artisans réalisaient des faïences, des porcelaines et des grès qui, d'après une étude des catalogues et des tarifs, s'adressaient à tous les types de publics, des plus fortunés aux plus modestes ${ }^{61}$. Par la modicité de son prix, une partie de cette vaisselle était

56 V. François, L. Vallauri, 2001, p. 545, fig. 11: 2; H. Amouric, Fl. RicheZ, L. VAlLAURI, 1999, p. 125-128.

${ }^{57}$ M.L. Von Wartburg, 2001, p. 379, fig. 7: 61, 62, fig. 10: 26 et 27.

58 M. Hahn, «Modern Greek, Turkish and Venetian Periods», in E. et B.P. HaLlaGER (eds.), The Greek-Sweedish Excavations at the Agia Aikaterini Square, Kastelli, Khania 1970-1987, vol. I, 1, Stockholm, 1997, pl. couleur: d, pl. 71: 12, pl. 76a: 1 et 2

59 J. VROом, 1998, p. 138-142.

${ }^{60}$ N. Cunomo di CAPrio, Ceramica rustica tradizionale in Puglia, Congedo Editore, Galatona, 1982.

${ }^{61}$ E. DECKER, «Sarreguemines au XIX ${ }^{\mathrm{e}}$ siècle : la faïence Utzschneider 1790-1914 — 
en effet à la portée d'un grand nombre de consommateurs. Une part de cette production était exportée vers les pays d'Europe mais pas seulement. En 1852, «Tous les beaux produits de la faïencerie de Sarreguemines étaient recherchés de toute la France, des cours de l'Europe et des principales villes de l'Orient et des deux Amériques » ${ }^{62}$. En 1889, la Grèce et la Turquie faisaient partie de ces marchés lointains. De 1892 à 1905, un certain Jacques Alberico représentait la faïencerie en Grèce, en Turquie et en Egypte ${ }^{63}$. Cependant la consultation des archives de la société atteint assez vite ses limites lorsqu'il est question de déterminer les types de production commercialisés dans cette partie du monde. L'examen d'un catalogue, imprimé en 1925 mais qui reprend des modèles créés dès 1880, rassemblant des bols, des saladiers, des soupières et des assiettes spécifiquement destinés à l'exportation, fournit quelques pistes quant aux objets fabriqués pour les marchés extérieurs ${ }^{64}$. Il propose une large gamme de vaisselle décorée dans laquelle pouvaient puiser, selon leurs goûts ou ceux de leurs clients, les grossistes étrangers. Sur la base de cette documentation, il est toutefois difficile de savoir quelles pièces étaient majoritairement choisies pour le marché oriental car, en l'absence de renseignements supplémentaires, on ne peut distinguer les décors faits pour l'Orient des décors orientalistes destinés à une clientèle européenne qui, dans la deuxième moitié du XIX ${ }^{\mathrm{e}}$ siècle, prisait fort cette iconographie nouvelle. En effet, comme le remarquait V. de Luynes, l'auteur du rapport sur la céramique à l'Exposition universelle de 1878, «dans ces dernières années, l'importation directe des produits de l'Orient par les ports du Havre et de Bordeaux a créé, pour les porcelaines et céramiques de toute nature, une concurrence fatale, en répandant et faisant accepter du public les décorations dans le goût arabe, persan, japonais et chinois ${ }^{65}$. Les producteurs français décidèrent alors «de combattre l'invasion en France de la céramique orientale en essayant non de l'imiter, mais de la remplacer par des produits ana-

contribution à une histoire des goûts et des styles au XIX ${ }^{\mathrm{e}}$ siècle », Thèse de doctorat soutenue à l'université de Nancy II, 2001, (microfiches), p. 94.

${ }^{62}$ F. Verronais, Supplément à la statistique du département de la Moselle, Metz, 1852, p. XXXV.

${ }^{63}$ H. Hiegel, Ch. Hiegel, La Faïencerie de Sarreguemines de 1870 à 1918, Musée de Sarreguemines, 1996, p. 97; E. DECKER, p. 94.

64 Je tiens à remercier M. Emile Decker, conservateur en chef des Musées de Sarreguemines, pour m'avoir transmis cette documentation et m'avoir permis d'en reproduire une partie.

${ }^{65}$ V. de LuYNES, 1878, p. 65. 
logues d'un coloris éclatant, moins monotone d'aspect, élégant et plus en harmonie avec les besoins et les goûts de notre époque ${ }^{66}$. C'est vraisemblablement en adoptant cette stratégie que les dessinateurs de Sarreguemines ont mis au point un certain nombre de compositions à la mode orientale tels que des décors «perses» constitués de longues tiges ondulées fleuries sur fond pointillé ou de rosaces composées de fleurs mauves alternant avec des lancettes et des fleurs rouges, des rinceaux persans et divers éléments géométriques évoquant l'architecture orientale ${ }^{67}$. Une soupière, proposée au marché de l'export, porte ces mêmes éléments décoratifs, le modèle est dit «Turc croissant lustré» (Pl. 3: 1), une autre est désignée «Bali brun», quant à celle dite «Timor» elle rappelle les porcelaines chinoises à émaux de la famille verte, ce dernier décor se déclinant aussi sur des assiettes plates dites «Canton peint lustré » et «Timor peint lustré». Si ces objets étaient sans doute destinés à des consommateurs européens amateurs d'exotisme, d'autres pièces semblaient plutôt réservées aux clients orientaux. Ainsi trouve-t-on, dans ce catalogue, des bols et des assiettes ornés d'un bandeau rouge sur lequel se détachent des étoiles associées à un croissant en réserve blanc (Pl. 3 : $2,3)$. Une variante consiste, sur une assiette, en un décor blanc de croissants de lune et d'étoiles réalisé au pochoir en émail sur fond de couleur brun $\operatorname{rose}^{68}(\mathrm{Pl} .3: 4)$. Ces éléments renvoient, à n'en pas douter, aux armoiries de l'Empire ottoman. Un bol décoré de manière identique, trouvé à Alep en Syrie, montre que les faïenceries de Sarreguemines n'étaient pas les seules à décliner ce motif puisque cet objet provient des manufactures de Lunéville en Lorraine. La reproduction du drapeau turc laisse croire que cette vaisselle bon marché était destinée à un public capable de saisir immédiatement le sens de l'image, c'est-à-dire les Ottomans eux-mêmes. De la même façon, un autre élément décoratif typiquement ottoman, à forte charge symbolique — il apporte pouvoir et protège du «mauvais oeil» - a sûrement été choisi pour la clientèle turque. Il s'agit du çintamani, un motif largement exploité par les Ottomans dans tous les domaines des arts appliqués depuis le $\mathrm{XVI}^{\mathrm{e}}$ siècle et notamment sur la vaisselle d'Iznik. Sur les bols de Sarreguemines, un seul des éléments du çintamani est exploité, il s'agit des sequins organi-

${ }^{66}$ Ibidem, p. 66.

${ }^{67}$ Ch. Bolender, Histoire et Histoires. Faïences de Sarreguemines 1800-1939, catalogue d'exposition, Musée historique, Strasbourg, 21 mars-1 ${ }^{\text {er }}$ juin 1986, p. 67, 68.

68 A. BEnedick, U. Radunz, Sarreguemines: la porcelaine, Sarreguemines, Ed. Pierron, 2002, DD 40. 
sés en bandeau (Pl. 3: 5). Sur le terrain, divers modèles de vaisselle de Sarreguemines ont été repérés. À Damas, plusieurs assiettes creuses à marli et un petit pot, en porcelaine opaque, constituent les importations les plus récentes mises au jour dans les fouilles de la citadelle. Elles portent une marque imprimée, un blason de Lorraine surmonté d'une couronne ${ }^{69}$, caractéristique des années 1875 (Pl. $3: 6$ et 7). D'autres objets de même origine sont présents au Sultanat d'Oman ${ }^{70}$ tandis que des «opaques de Sarreguemines» existent à Potamia (Chypre) et en Béo$\operatorname{tie}^{71}$. À Istanbul, on trouve des assiettes creuses à aile large, ornées de rinceaux de bryone - une plante grimpante de la famille des cucurbitacées — dont les nervures sont rehaussées d'or (Pl. 3: 8). Sur la marque imprimée au revers on lit, à l'intérieur d'une couronne de feuillage, «Bryonia U\&C». Ce décor se décline aussi en bleu sur une autre assiette vendue chez un antiquaire. Un modèle différent, repéré à Istanbul, consiste en une succession de bandeaux peints en orange ou rouge et ornés de motifs imprimés au tampon, des spirales flammées bleues et des fleurons trilobés noirs (Pl. 3: 9). La marque imprimée sous la base, formée du blason de Lorraine surmontée d'une couronne et entourée de l'inscription Sarreguemines et Digoin, permet de l'attribuer à la fin du $\mathrm{XIX}^{\mathrm{e}}$ siècle. Enfin, une assiette historiée, imprimée en noir, commémore la guerre de Crimée, autour de 1856 (Pl. 3: 10). La scène s'intitule «Une batterie turque à Roustchouk» et fait partie de série éditoriale. Ces faïences fines imprimées illustrant la guerre de Crimée ${ }^{72}$, ont remporté un vif succès et ont été largement diffusées dans toutes les couches de la population au milieu du XIX ${ }^{\mathrm{e}}$ siècle $^{73}$. En plus de Sarreguemines, elles étaient fabriquées dans les manufactures françaises de Longwy,

${ }^{69}$ E. DeCKer, C. TheVEnin, Guide de l'amateur des faïences de Sarreguemines, 1988, p. 33

${ }^{70}$ Information aimablement transmise par E. Decker.

${ }^{71}$ L. Vallaury, "Céramiques en usage à Potamia-Agios Sozomenos de l'époque médiévale à l'époque ottomane", Cahier du Centre d'Etudes Chypriotes 34, 2004, p. 229; J. VRoom, «Early Modern Archaeology in Central Greece: the Contrast of Artefact-Rich and Sherdless Sites», Journal of Mediterranean Archaeology 11.2, 1998, p. 138.

72 Procédé de décoration semi-mécanique selon lequel un dessin est reporté d'une plaque de cuivre gravée sur une assiette déjà cuite, à l'aide d'un matériau souple tel que du papier très mince.

73 M.-G. BeAuX-LAFFon, «Mutation des représentations et du goût au milieu du $\mathrm{XIX}^{\mathrm{e}}$ siècle. Iconographie de la guerre de Crimée sur faïence fine imprimée », in J.-M. Minovez (éd.), Faïence fine et porcelaine. Les hommes, les objets, les lieux, les techniques, Toulouse, CNRS-Université de Toulouse-le-Mirail, 2003, p. 181-217. 
Bordeaux, Choisy, Creil-Montereau, Gien et Saint-Gaudens (sud-ouest). Des exemplaires fabriqués dans ces centres sont présents à Istanbul. Ainsi cette assiette qui illustre La Question d'Orient en proposant «Une vue de Constantinople prise de Péra» fabriquée à Creil-Montereau (Pl. 4: 1). Sous la base, deux dragons encadrent la marque «L.M. Cie Porcelaine opaque». Une autre assiette à désert provient de la faïencerie de Gien et représente un épisode de l'Expédition d'Orient. La marque «Geoffroy \& Cie Porcelaine opaque, médaille exposition 1844 » permet de la dater entre 1851 et 1860 . Diverses faïences fines réalisées dans la manufacture de Creil-Montereau ont atteint le marché oriental. Ainsi les grands plats à marli trouvés à Damas et à Alexandrie, au décor floral en camaïeu de bleu imprimé qui s'apparente au modèle «Flora» daté vers $1867^{74}$ (Pl. 4: 2). Une autre production française, venue cette fois des manufactures de Saint-Amand-les-Eaux (Nord-Pas-de-Calais), est illustrée par une assiette peinte au petit feu ornée d'une couronne fleurie polychrome et marquée d'un blason peint en noir aux armes de la ville (Pl. $4: 3$ ) tandis qu'une assiette de même style se trouve emmurée dans la voûte de l'église de la Panagia Chriseleousa à $\mathrm{Empa}^{75}$. Enfin, si nous savons par les textes qu'à la fin du $\mathrm{XIX}^{\mathrm{e}}$ siècle, la fabrique Page et Rigal, à Salins (Jura) ${ }^{76}$, exportait vers l'Egypte des faïences blanches ou teintées ivoire et des pièces de faïence fine dure dite granit $^{77}$, aucun de ces objets n'a encore été identifié en Egypte.

G. Thierry, à l'occasion de l'Exposition universelle d'Anvers, remarquait que les porcelaines anglaises étaient inabordables alors que les services de faïences «exécutés par les usiniers anglais à des prix très bas,... font une concurrence redoutable aux produits similaires français ${ }^{78}$. Si les rapports consulaires et les statistiques montrent la suprématie des importations anglaises, les découvertes de terrain livrent effectivement un bel échantillonnage de productions du Staffordshire. On trouve à Istanbul: - une grande assiette creuse dont le marli est orné de rinceaux peints en polychromie dans un style orientalisant

${ }^{74}$ D. Guilleme-Brulon, La faïence fine française, 1750-1867, Paris, Ed. Massin, s.d., p. 40-47.

75 I. HADJIKYRIAKOS, 2006, p. 402, Tav. III.

76 J.-M. Olivier, «L'essor de la faïence fine de Salins» dans J.-M. Minovez (éd.), Faïence fine et porcelaine. Les hommes, les objets, les lieux, les techniques, Toulouse, CNRS-Université de Toulouse-le-Mirail, 2003, p. 127-138.

77 M. J. LoEBnitz, 1891, p. 240.

78 G. THIERrY, «La Céramique» dans Exposition universelle d'Anvers 1855, Paris, 1886, p. 13. 
(P1. 5: 1). La marque, imprimée sous le marli, désigne ce modèle du nom de $«$ Bagdad ${ }^{79}$. Cette faïence fine, fabriquée entre 1851 et 1862 , est un produit des manufactures de Pinder, Bourne \& Hope à Burslem; - un grand plat de service à décor végétal imprimé en bleu appelé «Bouquet» provient de l'usine de William Lowe, à Longton (Pl. 5 : 2). La marque, un voilier entouré d'un cordage, permet de l'attribuer à une phase de fabrication comprise entre 1874 et 1931. Dans les fouilles du manoir de Potamia ${ }^{80}$, à Chypre, une tasse à café sans anse, fabriquée dans le style ottoman et décorée d'un décor végétal peint en bleu, marquée Copeland \& Garrett vient des officines de Stoke-on-Trent, elle peut être datée entre 1833 et 1847 (Pl. 5 : 3). De la faïence fine imprimée, de la firme Powell, Bishop and Stonier Ltd., de la fin XIX ${ }^{\mathrm{e}}$ siècle, est apparue dans une prospection en Béotie ${ }^{81}$. Et on ne compte plus les plats et les tessons plus nombreux encore de vaisselle imprimée en camaïeu bleu de cobalt ou gris, au décor Willow Pattern créé dans le Staffordshire en 1788 ou 1789. Ce décor, qui illustre les amours malheureuses de la fille d'un mandarin chinois, est composé d'une grammaire de style sino-japonais avec barrière, pagode, pin, saule pleureur, pont, jonque et couple de colombes. Largement exploitée par les fabricants du Staffordshire, cette composition a été reprise par les manufactures de Calais en France, de Jemmapes en Belgique et de Villeroy \& Boch au Luxembourg. Des fragments de ce type d'assiette ont été trouvés dans les fouilles du manoir de Potamia et à Famagouste à Chypre, à Istanbul ainsi qu'à Alexandrie et à Pleven en Bulgarie ${ }^{82}$ (Pl. 5: 4). Chez les antiquaires d'Istanbul et de Bursa leur présence en nombre atteste un vaste marché. D'autres décors d'assiettes du Staffordshire sont spécifiquement réalisés pour le marché grec, telles que les pièces illustrant la guerre d'Indépendance à travers ses héros ou encore des assiettes ornées du buste d'Alexandre le Grand ${ }^{83}$, des images accompagnées d'inscriptions grecques.

Dans les documents commerciaux, la Belgique fait souvent partie des pays exportateurs de faïences. Les faïences fines belges sont essentiellement représentées au Proche-Orient par les productions de la Fabrique

\footnotetext{
${ }^{79}$ Les noms des motifs deviennent importants et sont souvent imprimés au verso des pièces.

${ }^{80}$ L. Vallauri, 2004, p. 236, fig. 15.

81 J. VROOM, 1998, p. 138.

${ }^{82}$ L. Vallauri, 2004, p. 237, fig. 16; J.W. HaYes, 1992, p. 344, pl. 51 :I.

83 J. VRoom, 2005, p. 188, 189.
} 
Impériale et Royale de Nimy, près de Mons, fondée en $1789^{84}$. Les procès-verbaux du conseil d'administration de la faïencerie «Société anonyme de la faïencerie de Nimy», précisaient que des agents de la manufacture étaient en poste à Beyrouth en 1894, à Damas en 1896 et, au début du XX $\mathrm{XX}^{\mathrm{e}}$ siècle, au Caire ${ }^{85}$. Plusieurs grands plats de Nimy, à décor géométrique couvrant peints en camaïeu bleu, datés du XIX ${ }^{\mathrm{e}}$ siècle, sont apparus dans les fouilles de la citadelle de Damas (Pl. 6: 1). Dans cette ville, ainsi qu'à Istanbul, il n'est pas rare de trouver de tels objets chez les antiquaires (Pl. 6:2,3). En Haute Egypte, les fouilles d'une maison à Cheikh abd el-Gourna, dans la région de Louqsor, ont livré la base d'une assiette blanche, imprimée au revers avec la marque de la fabrique $^{86}(\mathrm{Pl} .6: 4)$. Une pièce pour l'instant exceptionnelle — à moins qu'elle ne soit représentative d'une série plus large - présentée au musée du Vieux-Nimy, laisse croire qu'une partie de la production était destinée au marché turc. En effet, l'aile de cette assiette porte un large bandeau de rinceaux végétaux qui s'enroulent autour de vases chinois, tandis qu'un médaillon central est calligraphié en ottoman. L'inscription est datée de l'année de l'hégire 1296, soit 1880 de l'ère chrétienne.

Des faïences fines réalisées dans la fabrique Richard-Ginori de Mondovi dans le Piémont, fondée par Carlo Ginori en 1746, sont aussi présentes, à la fin du XIX ${ }^{\mathrm{e}}$ siècle, en Méditerranée orientale. Des exemplaires complets ou fragmentaires de cette manufacture ont été repérés à Istanbul et à Chypre $^{87}$ (Pl. 2: 3).

\section{Porcelaine}

La valeur en franc des porcelaines importées dans tout l'Empire ottoman était, en 1890, de 382806 f., en 1891, de 386426 f. et, en 1892, de 460043 f. Les expéditions n'étaient pas toutes de même nature. Il semblait exister des marchés spécifiques. Les porcelaines étaient largement distribuées à l'exception des villes d'Edirne, de Dédéagatch, de Monastir, d'Aïvaly, de Samos et de Rhodes qui n'en reçurent aucun colis entre 1870 et 1873. L'approvisionnement de Samsoun était un peu différent

84 B. PringIERs, Faïence et porcelaine en Belgique 1700-1881, Ed. Racine, 1999, p. 37-38.

85 E. BRUYERE, Manufacture de Nimy: quelques recherches effectuées en 1992, s.d., s.p.

86 Communication personnelle de L. Bavay (Centre de recherches archéologiques, Université libre de Bruxelles) que je remercie pour sa collaboration.

87 L. VALLAURI, 2004, p. 229. 
de celui des autres ports, la France et l'Autriche apparaissant comme d'assez faibles fournisseurs pour ces produits. Et Trébizonde recevait exclusivement de la porcelaine que ce soit pour une diffusion régionale ou à destination de la Perse. Par le port de Trébizonde, le sandjak (département) de Van était approvisionné en porcelaines et verrerie ${ }^{88}$. Les rédacteurs des documents statistiques concernant la Turquie d'Europe et la Turquie d'Asie, outre qu'ils ne précisent guère le type de porcelaine transporté, associent presque toujours les porcelaines à la verrerie et au cristal. Il est donc difficile d'évaluer le poids réel des importations de porcelaine. De plus, les pays expéditeurs sont désignés sans qu'il soit possible de savoir s'ils ont commercialisé conjointement verre et porcelaine ou seulement l'un ou l'autre. Malgré ces restrictions, il semble incontestable que l'Autriche et l'Allemagne ont vendu les porcelaines les plus chères, leur valeur totale en franc étant de 2 à 6 fois plus élevée que celle du deuxième pays exportateur qu'il s'agisse, suivant les ports, de la France ou de l'Angleterre. Il n'y a qu'à Alexandrette, en 1890 et 1892, que le coût des importations françaises de porcelaine est plus élevé que celui de l'Autriche. Parmi les pays exportateurs, il est assez surprenant de trouver aux côtés des pays d'Europe, la Grèce qui envoie 6 tonneaux de porcelaine en Crète en 1892, à l'évidence de la vaisselle réexpédiée. La Suède et le Danemark apparaissent, dans ces textes, comme des fournisseurs probables de porcelaines - encore que la verrerie soit aussi associée aux exportations. Si les manufactures de Marieberg en Suède fabriquaient des porcelaines en 1777-1778 et celles de Rörstrand des faïences fines et des porcelaines tendres et dures à partir du milieu du XIX ${ }^{\mathrm{e}}$ siècle, aucune de ces pièces n'a encore été identifiée en Méditerranée orientale. Il en va de même pour les fabrications de la manufacture de Copenhague au Danemark fondée en 1775. La Turquie importait aussi des porcelaines de Russie — en 1890, dans le sandjak de Van, des faïences venaient de Russie — peut-être fabriquées dans la grande manufacture de Kouznetzoff fondée en 1832 à Moscou. Le commerce de cette société colossale se faisait en Russie, dans les provinces balkaniques, en Pologne, dans les contrées des Cosaques du Don, en Sibérie, à Tachkent, dans le Transcaspien, à Boukhara, Khiva, dans le Caucase, en Bessarabie, en Perse et en Turquie. Selon M.J. Loebnitz,

${ }^{88}$ Le sandjak de Van ne recevait pas de poterie. L'existence dans le vilayet (province) de 60 manufactures qui produisaient 300000 pièces et en exportaient 24000 explique sans doute l'absence des importations de terrailles. 
«Cette porcelaine a quelques rapports avec celle de Limoges. Tous les décors sont au feu de moufle. La faïence fine ne présente pas de décors sous couverte. Les assiettes en faïence sont généralement très épaisses, la pâte paraît bonne ainsi que la couverte. Tout l'ensemble des décors a bien le caractère russe. Il s'agit d'assiette au dessin très délicat dans le caractère russe, elles sont peintes polychromes avec des rehauts d'or en relief $»^{89}$.

Les archives commerciales ne permettent pas de distinguer les produits bon marché des produits coûteux. À la lecture des statistiques livrées par V. Cuinet, comment faire la différence entre les véritables porcelaines dures fabriquées en Prusse, en France et en Angleterre, et les porcelaines tendres, meilleur marché ? Selon V. de Luynes, ce sont à la fois des porcelaines communes et fines qui étaient exportées vers la Turquie, à la fin du XIX $\mathrm{X}^{\mathrm{e}}$ siècle (tableau 3), ce que confirment des sources relatives à la vaisselle utilisée à la cour ottomane. Les porcelaines importées d'Europe allaient de paire avec une occidentalisation des mœurs. Dans les milieux favorisés de l'Empire, de nouveaux aliments avaient fait leur apparition dans les cuisines ${ }^{90}$. Ces mets étaient servis au cours de repas dont l'étiquette avait changé: les convives se retrouvaient autour d'une table et non plus d'un plateau, s'asseyaient sur des chaises plutôt que sur le sol, employaient une fourchette et non plus leurs doigts pour porter les aliments à leur bouche. Cette transformation progressive s'étendit sur un siècle, de 1800 à 1900 , durant lequel coexistèrent deux manières de table: alaturka, c'est-à-dire dans le style ottoman et alafranga, dans le style européen ${ }^{91}$. Dans ce contexte, de nouveaux services de table importés d'Europe firent leur apparition. Des importations en provenance des manufactures de Meissen et de Vienne, groupées sous le nom générique ottoman de saksunya, sont parvenues en Turquie dès le $\mathrm{XVIII}^{\mathrm{e}}$ siècle $^{92}$. Les inventaires du Trésor du palais impérial à Istanbul attestent la présence de vaisselle de Prusse et d'Autriche faite selon le goût des Ottomans: des grands plats profonds avec leurs couvercles, de

${ }^{89}$ M.J. LoEBNITZ, 1891, p. 214-215.

90 Ö. SAmancI, «Culinary Consumption Patterns of the Ottoman Elite during the First Half of the Nineteenth Century», S. FAROQHI, C.K. NeumanN (eds.), The Illuminated Table, the Prosperous House, Würzburg, Beiruter Texte und Studien 73, 2003, p. 161184.

${ }^{91}$ Mahmud II (1808-1939) est le premier sultan à avoir mangé attablé. Ibidem, p. 161.

92 F.M. GöceK, Rise of the Bourgeoisie, Demise of Empire: Ottoman Westernization and Social Change, Oxford, New York, 1996, p. 40, 103. 
petites coupes à couvercle, des coupes à dessert, des tasses à café de type fincan et des aşurelik, des aiguières pour servir l'aşure (une sorte de pudding $)^{93}$. Ces pièces étaient exécutées à la commande dans le goût des clients turcs qui fournissaient des modèles. À Damas, on recense seulement quatre tasses de porcelaine de Meissen fort endommagées. Des tasses à café de même origine ont été mises au jour à Tripolii" à Acre ${ }^{95}$ et à Jérusalem ${ }^{96}$ ainsi qu'à Aphrodisias en Anatolie ${ }^{97}$. À leur tour, la fabrique de Vincennes, en 1738, puis la manufacture royale de Sèvres, à partir de 1805, fabriquèrent des assiettes et des coupes de porcelaine destinées à la clientèle ottomane fortunée ${ }^{98}$. Au début du XIX X $^{\mathrm{e}}$ siècle, au Palais impérial, on préférait la porcelaine française et saxonne et la vaisselle anglaise aux porcelaines chinoises et autres productions de vaisselle fine ottomane qui avaient tant impressionné les hôtes du sultan au cours du XVIII ${ }^{\mathrm{e}}$ siècle $^{99}$. En 1854, sont énumérés dans les registres d'acquisition de la Cuisine impériale divers types de pièces françaises et saxonnes: Fransiskâri tabak (assiette française) et Fransiskâri hoşab kase (coupe française pour la compote) mais aussi beyaz Saksonya balık tabağl (assiette saxonne blanche pour le poison), beyaz Saksonya şorba tası ma kapak (assiette à soupe saxonne, blanche avec couvercle), Saksonya dalgall çukur tabak (assiette saxonne avec un décor ondulé), beyaz Saksonya zerde kase ma kapak (coupe blanche saxonne avec couvercle pour le riz safrané sucré), Saksonya kahvealt tabăğ (assiette saxonne pour le petit-déjeuner), Saksonya salata tabăg $l$ (assiette à salade saxonne) et Saksonya tuzluk (salière de Saxe) ${ }^{100}$. Les produits importés au Palais impérial ne consistaient pas uniquement en vaisselle de luxe

93 J. RABY, Ü. YüCEL in R. KRAHL, Chinese Ceramics in the Topkapı Saray Museum, a Complete Catalogue, vol. I et II, Londres, Sotheby's Publications, 1986, p. 38, Table 8, p. 53. Pour des exemples, voir les collections du Sadberk Hanım Museum, Istanbul, 1995, p. 117-119.

94 H. Salame-Sarkis, Contribution à l'histoire de Tripoli et de sa région à l'époque des Croisades: problèmes d'histoire, d'architecture et de céramique, BAH 106, Paris, 1980, p. 226.

95 G. Edelstein, M. Avissar, 1997, p. 133, pl. IV : 5a, b.

96 J. Carswell, C.J.F. Dowsett, Kütahya Tiles and Pottery from the Armenian Cathedral of St. James, Jérusalem, vol. I, 1972, fig. 32.

97 V. FranÇOIS, 2001, p. 183-185.

98 Ö. SAMANCI, 2003, p. 179.

99 Sur les impressions de l'ambassadeur de Pologne par exemple voir N. SAKAOGLU, «Sources for our Ancient Culinary Culture», in S. FAroqHi, C.K. Neumann (eds.), The Illuminated Table, the Prosperous House, Würzburg, Beiruter Texte und Studien 73, 2003 , p. 56.

100 Ö. SAMANCI, 2003, p. 180. 
puisque, selon les archives des cuisines, au cours du $\mathrm{XIX}^{\mathrm{e}}$ siècle, des porcelaines de Dresde étaient utilisées pour le service quotidien. Elles provenaient probablement d'une des manufactures de Villeroy \& Boch construite à Dresde en $1853^{101}$.

MODALITÉS DU COMMERCE DE LA VAISSELLE

La multiplication des centres producteurs de vaisselle à travers toute l'Europe a généré une production abondante de faïences fines, à un prix de revient très bas, destinée à une large clientèle. Ainsi qu'en attestent les sources écrites, l'Empire ottoman constituait un marché non négligeable pour les grandes manufactures d'Europe qui y ont aussi exporté terrailles, jarres et porcelaines.

Selon les rapports consulaires, faïences et porcelaines étaient embarquées dans les ports de Marseille, de Savone, de Livourne et de Trieste. Cette ville, alors autrichienne, devenue un grand carrefour commercial, a connu dans la première moitié du $\mathrm{XIX}^{\mathrm{e}}$ siècle une période de grande prospérité favorisée par la construction de la ligne de chemin de fer qui la reliait à Vienne et par laquelle des caisses de vaisselle provenant des grandes manufactures de porcelaines de Saxe, d'Autriche et de Hongrie circulaient jusqu'à ce port de l'Adriatique. Les productions de vaisselle européenne étaient transportées par bateau à vapeur ou chargées sur des voiliers et, une fois débarquées dans les grands ports de l'Empire, elles pénétraient plus avant dans les terres au moyen du chemin de fer. Ainsi sur la ligne Constantinople-Andrinople-Philippopoli(Plovdiv)-Sarembey-Bellova, ce sont 50 tonnes de poteries qui ont circulé durant l'année $1890^{102}$. Sur la ligne Constantinople-Andrinople-Philippopoli(Plovdiv)Bellova-Tirnovo-Yamboli-Koukéli-Bourgas-Dédéagach, soit 817 km, 37 tonnes de poterie et de faïence ont été transportées en 1891 et 65 tonnes l'année suivante ${ }^{103}$. Les trains roulant sur les 232 km entre Haidar-Pacha

101 À la fin du XIX ${ }^{\mathrm{e}}$ siècle, c'était l'usine la plus importante du groupe. Entre Moselle et Sarre, l'aventure céramique de Villeroy \& Boch, Metz, Editions Serpenoise, 2003, p. 45. Rapports du jury mixte international publiés sous la direction de S.A.I. le Prince Napoléon, président de la commission impériale, Paris, 1856, p. 948.

${ }_{102}$ Chambre de commerce française de Constantinople, année 1890, Compte rendu des travaux, Constantinople, 1891, p 223.

${ }^{103}$ Chambre de commerce française de Constantinople, Compte rendu des travaux, année 1891, Constantinople, 1893, p. 271, 310; Chambre de commerce française de Constantinople, Compte rendu des travaux, année 1892, Constantinople, 1893, p. 243, 273. 
(Istanbul) et Biledjik (Asie Mineure) ont acheminé, en 1891, un peu plus de 23 tonnes de poterie et de faïence ${ }^{104}$. Sur la ligne Salonique-Mitrovitza \& Uskub (Skopje)-Zibeftché, soit $449 \mathrm{~km}, 25$ tonnes de poterie et de faïence ont circulé en $1892^{105}$. Pour cette même année, parmi les marchandises transportées en grande et petite vitesse sur les $578 \mathrm{~km}$ de la ligne Haidar-Pacha (Istanbul)-Angora (Ankara), on comptait 20 tonnes de poterie et de faïence soit un peu plus du tiers du poids des marchandises transportées.

Le commerce de la vaisselle française au Levant, en Roumélie et en Anatolie était conséquent. Cependant, à en croire les experts, il aurait pu s'y développer davantage. Lors de l'Exposition universelle d'Anvers en 1885, G. Thierry militait en faveur d'un rattachement des agents consulaires français au ministère du Commerce et de l'Industrie pour faciliter les affaires commerciales de la France à l'export. Ces agents auraient eu en charge la protection des marques et des modèles, et auraient pu renseigner les nationaux sur les modalités d'importations et d'exportations. Attentifs aux désirs des autochtones, ils auraient permis de fabriquer et de vendre des produits céramiques en harmonie avec les goûts, les habitudes et les besoins des consommateurs de ces pays ${ }^{106}$. De la même façon, le consul général de France à Beyrouth, en 1889 et 1890, souhaitait que les grossistes encouragent les fabricants à réaliser des porcelaines spécifiquement pour le marché oriental, prenant en compte les goûts des clients, leur «amour du clinquant» et ceci à des prix raisonnables. Dans son rapport sur la céramique à l'Exposition universelle de 1889, M.J. Loebnitz voulait «que l'industrie nationale soit davantage favorisée et encouragée à l'étranger par nos agents consulaires ${ }^{107}$. Il soulignait lui aussi le rôle des marchands dans l'élaboration de nouveaux modèles : «Les marchands, en effet, donnent souvent un concours précieux aux manufacturiers en leur signalant les modèles et les décors qui répondent le mieux aux goûts et aux besoins des consommateurs ${ }^{108}$. Des agents des grandes et petites manufactures françaises avaient pignon sur rue à Constantinople. Dans les Comptes-rendus des travaux de la chambre de commerce française en 1892, on trouve mention de M. Barni

104 Chambre de commerce française de Constantinople, Compte rendu des travaux, année 1891, Constantinople, 1892, p. 268.

105 Ibidem, p. 282, 301.

106 G. THIERRY, 1886, p. 16.

107 M.J. LoEBNITZ, 1891, p. 207.

108 Ibidem, p. 192. 
et Rigovi, fabricants de porcelaines à Limoges (Haute-Vienne); de Boulenger \& Cie, de la faïencerie de Choisy-le-Roy (Seine); de A. Pillivuyt $\&$ Cie, de la manufacture de porcelaines à Mehun-sur-Yèvre (Cher). Des publicités témoignent de l'existence de revendeurs tel Hte Décugis, installés 468 Grande rue de Péra, qui avait un dépôt pour les porcelaines de Limoges et les cristaux de Baccarat. Dans l'Annuaire oriental du commerce, publié à Constantinople par Cervati Frères \& $C^{\text {ie }}$ en 1896, les marchands d'assiettes et de verrerie, de cristaux et de porcelaines étaient répertoriés pour les villes de Janina, Athènes, Corfou, Volo et Syros en Grèce ${ }^{109}$.

Cette étude, de même que celle conduite par M. Milwright, cherche à améliorer notre connaissance du commerce de la vaisselle en Méditerranée orientale et dans les Balkans, à la fin de l'époque ottomane, pour évaluer la place que ces importations ont occupé par rapport aux productions locales dans le cadre de la montée de l'impérialisme culturel et économique des pays d'Europe occidentale. Le volume de ces importations en Turquie était tel que les voyageurs européens se plaignaient de la présence, dans les bazars, de cette vaisselle si peu exotique à leurs yeux mais qui, pour les clients orientaux, représentait sans doute une forme de modernité. L'arrivée massive de cette vaisselle bon marché ne fut pas sans conséquences sur les productions locales. M. Milwright a relevé, dans le Dictionary of the Crafts of Damascus, établi par alQasimi autour de 1890, plusieurs commentaires témoignant du déclin des métiers de potier et de réparateur de porcelaine à Damas causé par le prix bas de la vaisselle importée ${ }^{110}$. Pour la Roumélie, l'Anatolie, Chypre et les îles de l'Egée, il est difficile d'estimer la part prise par ces importations sur le marché de la céramique. En effet, on sait encore peu de choses sur les productions de ces régions à la fin de l'époque ottomane. Bien évidemment, des marmites, des jarres et autres pots de stockage étaient fabriqués dans l'Empire. Les marmites de Grèce, d'Anatolie, de Chypre et de Samos approvisionnaient les marchés orientaux de même que les jarres de Koroni, de Crète, de Tokat et de Sivas. Cela n'a pas empêché l'importation, dans ces régions, de jarres de Biot et des Pouilles ou de marmites de Vallauris pour ne citer qu'elles. Pour leur

109 Annuaire oriental du commerce, publié à Constantinople par Cervati Frères \& $\mathrm{C}^{\mathrm{ie}}$, 14 ${ }^{\mathrm{me}}$ année 1896 (Hégire 1313-1314), Constantinople.

110 M. Milwright, 2008, p. 121-152. 
part, les ateliers de Didymotique en Thrace et de Çanakkale dans les Dardanelles fournissaient une partie de la vaisselle de service et de table, des poteries peintes et glaçurées au plomb. Colorée mais d'aspect rustique, cette vaisselle ne pouvait rivaliser avec les céramiques émaillées et surtout avec les faïences fines venues d'Europe dont la qualité et la décoration n'avaient rien de comparable. Dans le domaine des porcelaines, plusieurs initiatives furent prises pour concurrencer localement le marché européen. Ahmed Fethi Pacha, ministre de l'Arsenal, créa en 1845 la fabrique de porcelaine d'Incirli à Beykoz (un village sur la côte asiatique du Bosphore). Elle fonctionna une trentaine d'années. La vaisselle y était fabriquée selon des techniques européennes et signée « eseri Istanbul». Des assiettes, des coupes, des plats et des cruches à fond blanc étaient ornés de fleurs colorées qui étaient alors populaires sur les porcelaines occidentales. Le bouton de préhension des couvercles était souvent en forme de fruits, de légumes ou de fleurs. Pour des raisons financières et à cause d'une mauvaise maintenance, la fabrique ferma rapidement ses portes. En 1893, le sultan Abdül-Hamîd II fonda la manufacture de Y1ldız afin de répondre à la demande croissante des consommateurs aisés pour la vaisselle de porcelaine et fournir des substituts aux importations de Sèvres et des autres manufactures européennes. L'usine fut d'abord dirigée par un Français. Les machines et les matières premières dont le kaolin étaient importées de France, de Sèvres et de Limoges, et ce sont encore des artisans français qui, au début, assurèrent la fabrication. La porcelaine ornée de portraits de sultan, de vues d'Istanbul et de guirlandes de fleur dans le goût turc avait pour marque une étoile et un croissant. En 1909, la «Yıldız Çini Fabrikası» cessa son activité. Il était moins coûteux d'importer des porcelaines européennes que de fabriquer de tels objets à Istanbul. Le développement des recherches concernant les productions ottomanes tardives et la prise en compte plus systématique, sur les chantiers de fouilles, des importations des $\mathrm{XVIII}^{\mathrm{e}}$ et $\mathrm{XIX}^{\mathrm{e}}$ siècles devraient permettre de compléter le tableau du marché de la vaisselle dans l'Empire ottoman dont j'ai dessiné une première esquisse. 

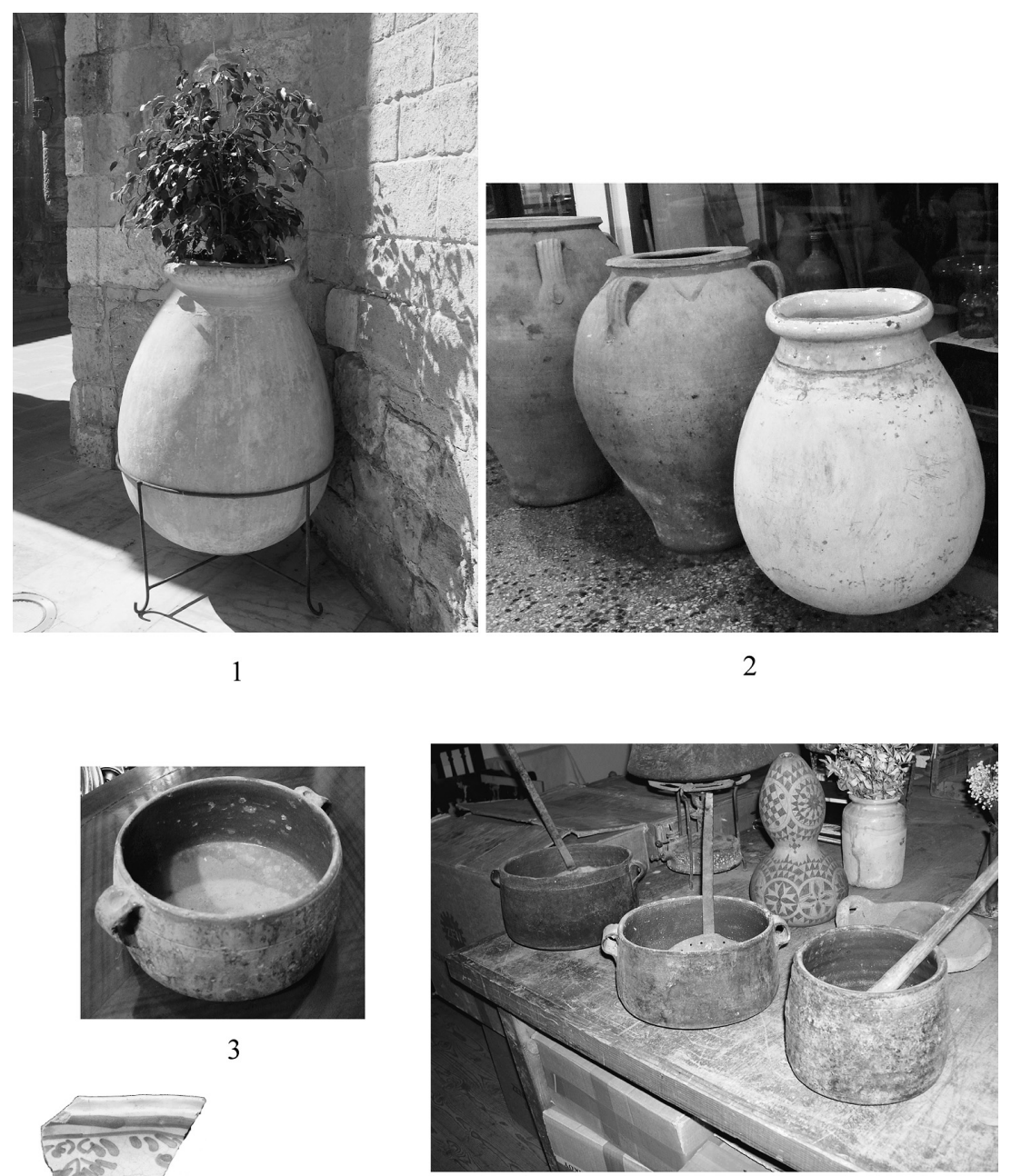

4

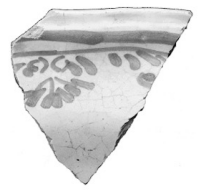

5

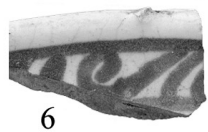

Pl. 1 : Jarres de Biot à Larnaka (1) et à Istanbul (2), jarres crétoises (2); marmites de Vallauris à Istanbul (3) et dans les Troodos à Chypre (4); faïences de Moustier (5) et de Varages (6) à Damas. 

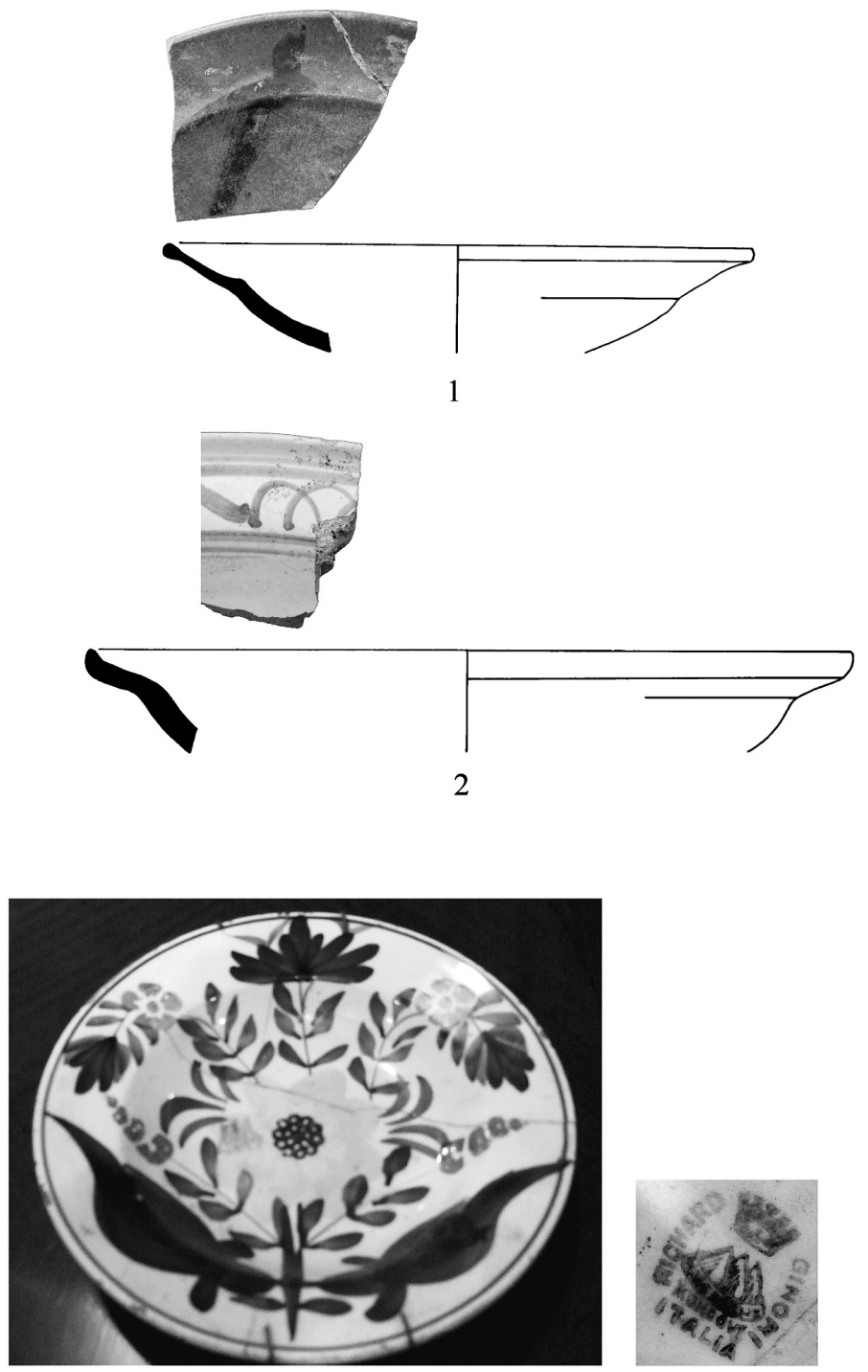

3

P1. 2 : Céramique italienne à "taches noires" d'Albisola (1) et faïence de Grottaglie (2) trouvées à Damas ; assiette de faïence fine de Mondovi (3) retrouvée à Istanbul. 


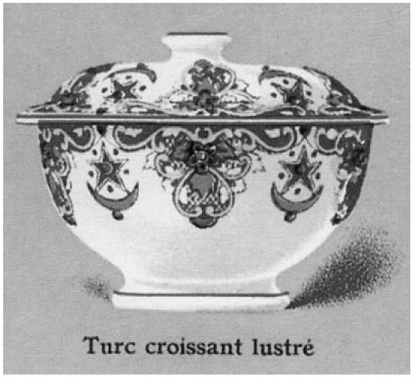

1
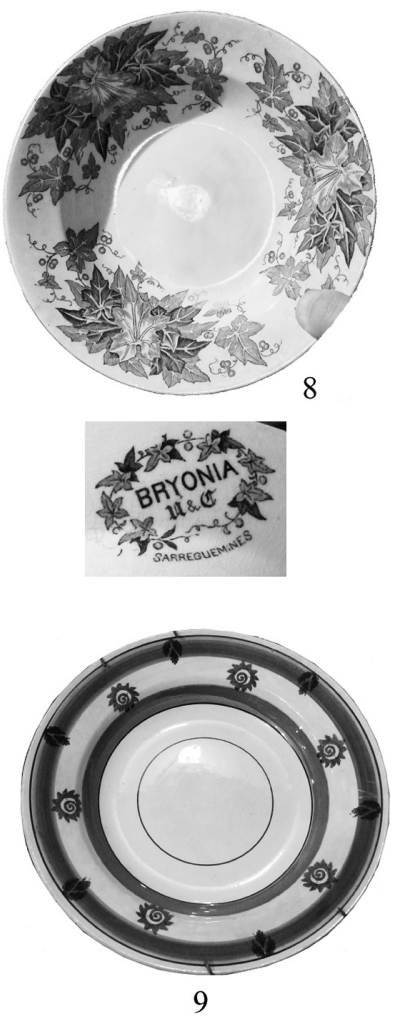

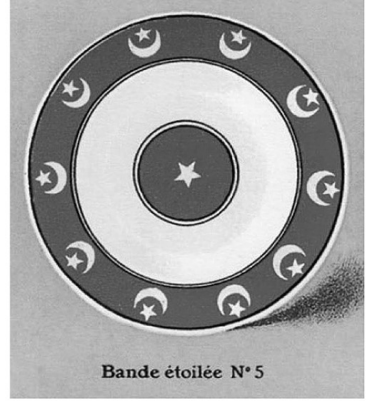

2
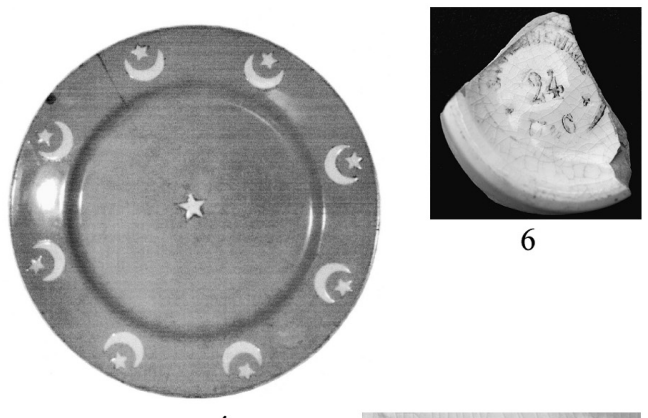

6

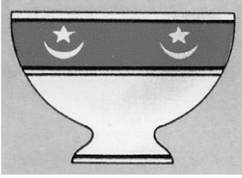

3

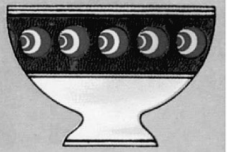

5
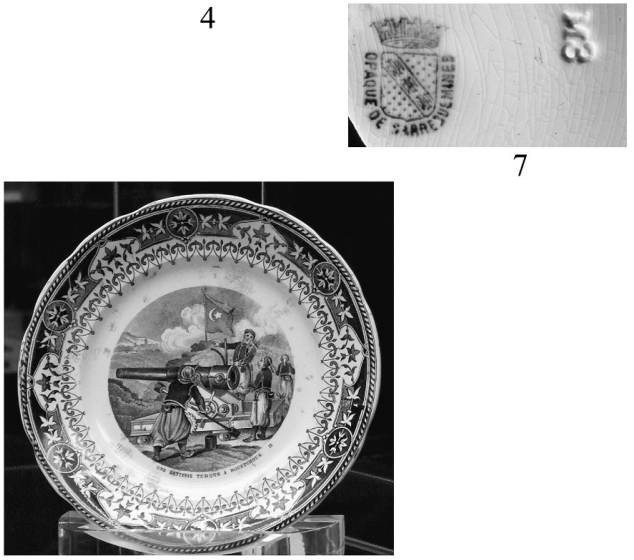

10

P1. 3 : Vaisselle de Sarreguemines proposée à l'exportation (1-5), et trouvée à Damas $(6,7)$ et à Istanbul $(8-10)$ 


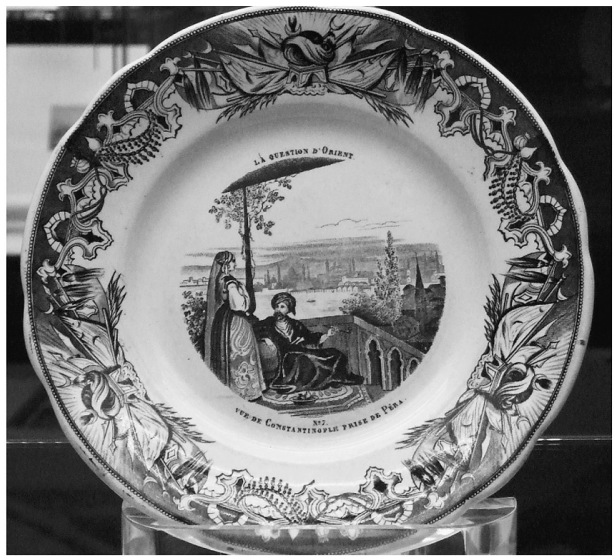

1
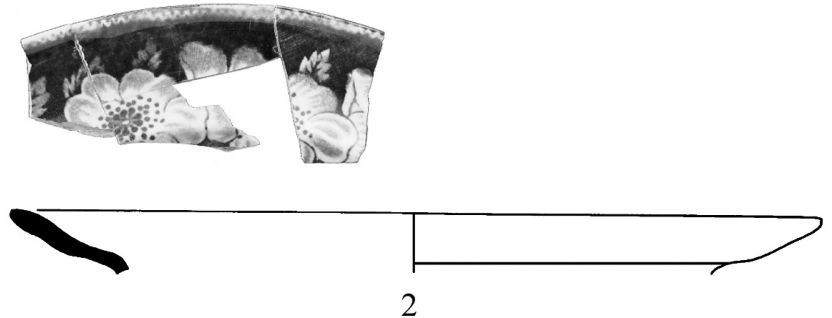

2
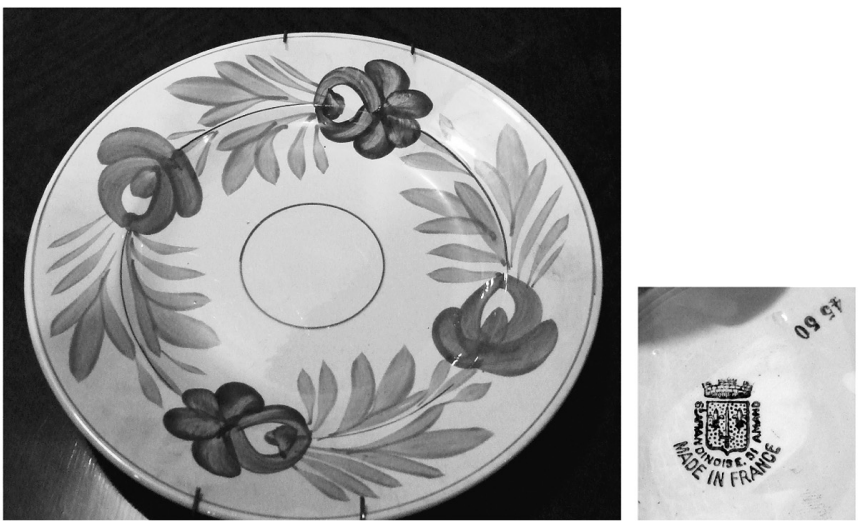

3

Pl. 4 : Assiettes des manufactures de Creil-Montereau trouvées à Istanbul (1) et à Damas (2) et assiette de Saint-Amand-les-Eaux (3) trouvée à Istanbul. 

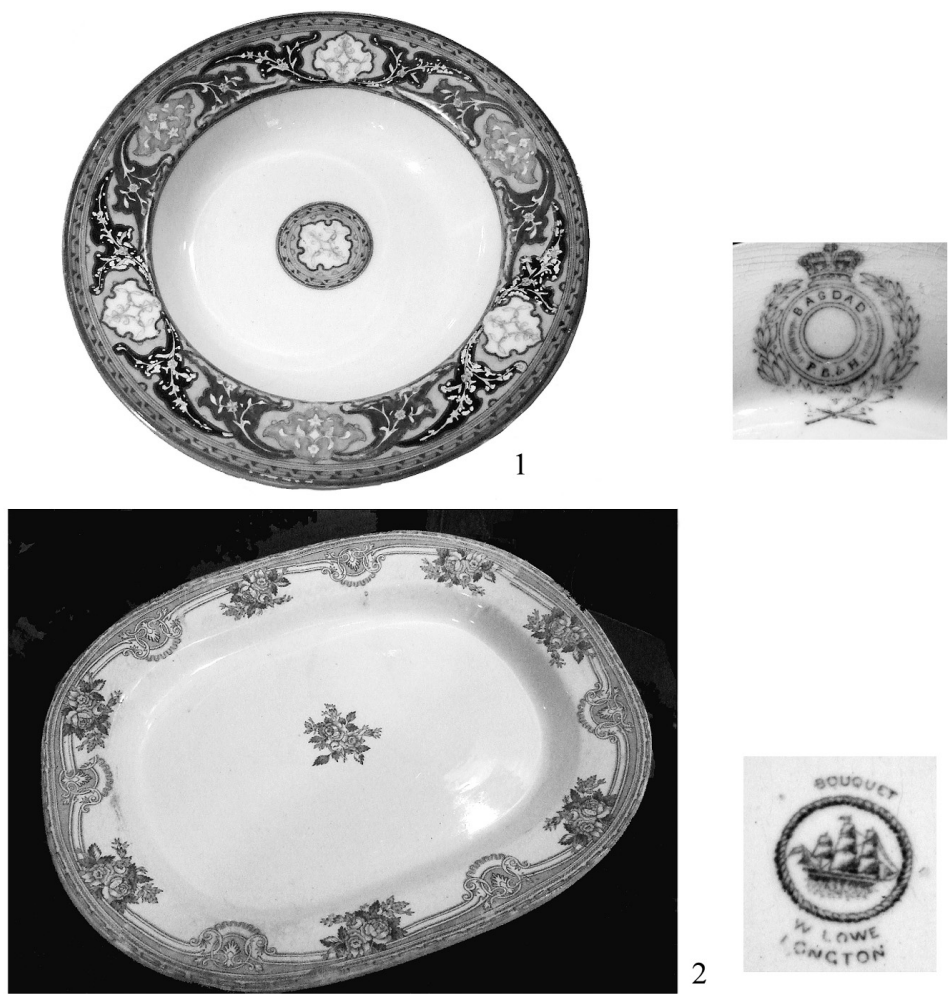

2
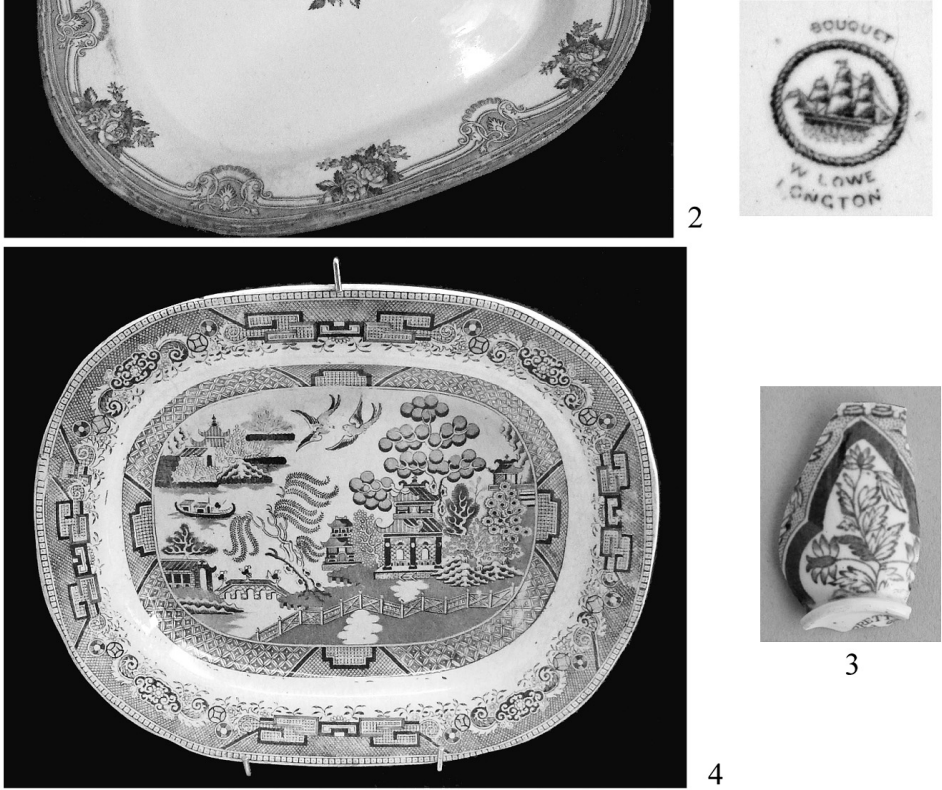

3

Pl. 5 : Vaisselle des manufactures anglaises du Staffordshire retrouvée à Istanbul $(1,2)$, à Potamia à Chypre (3) et à Pleven en Bulgarie (4) 


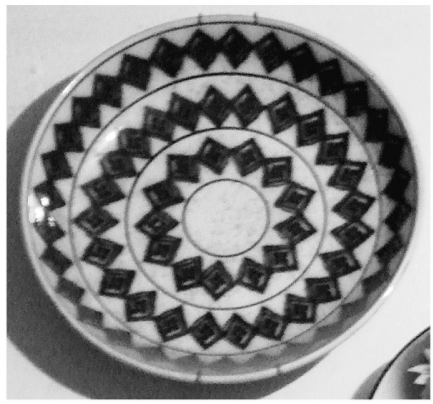

2
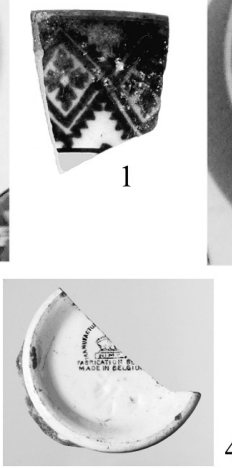

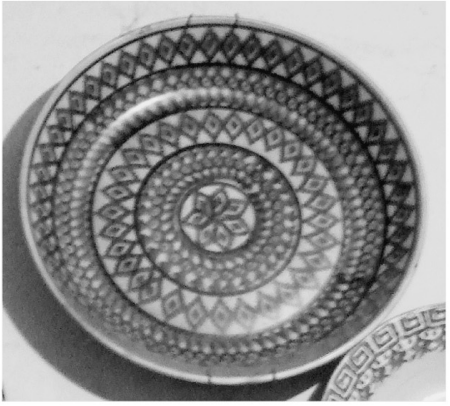

3

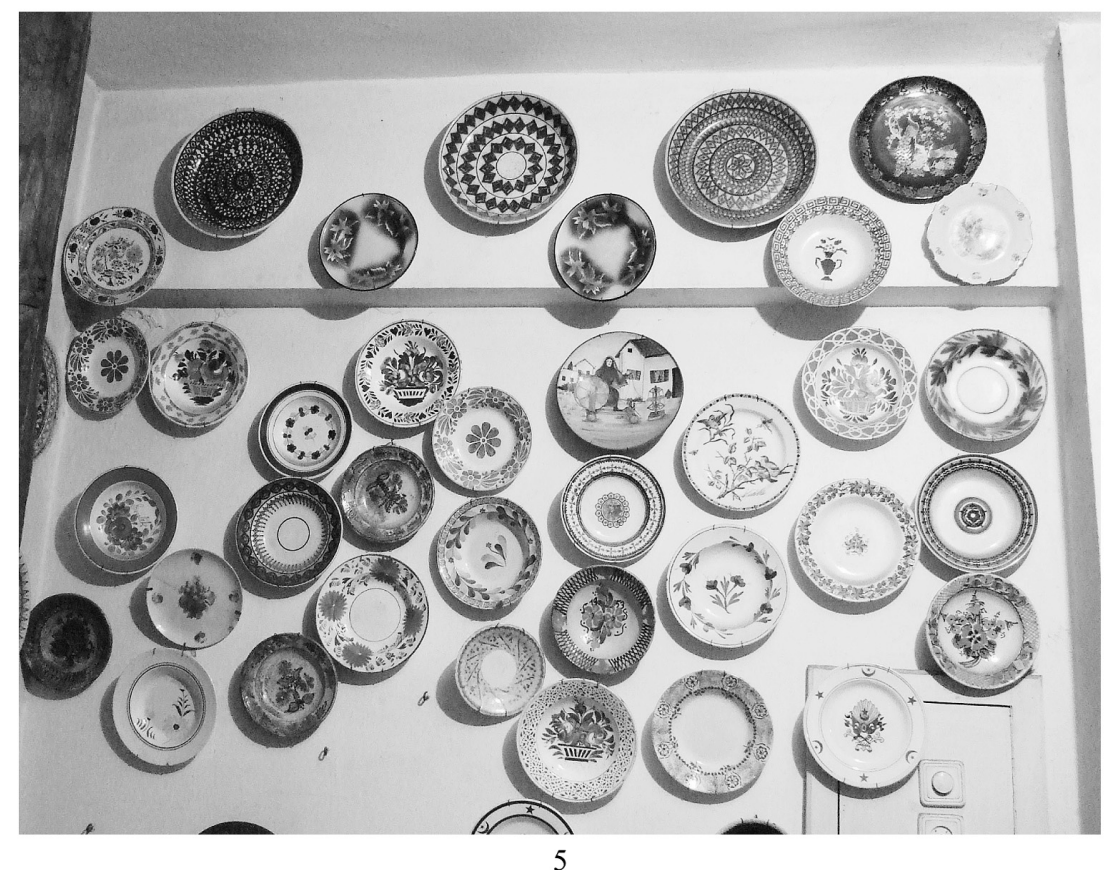

Pl. 6 : Vaisselle de la manufacture de Nimy trouvée à Damas (1), à Istanbul $(2,3)$ et à Louxor (4). Echantillonnage de productions européennes et turques chez un antiquaire d'Istanbul (5). 
JARRES, TERRAILLES, FAÏENCES ET PORCELAINES EUROPÉENNES 119

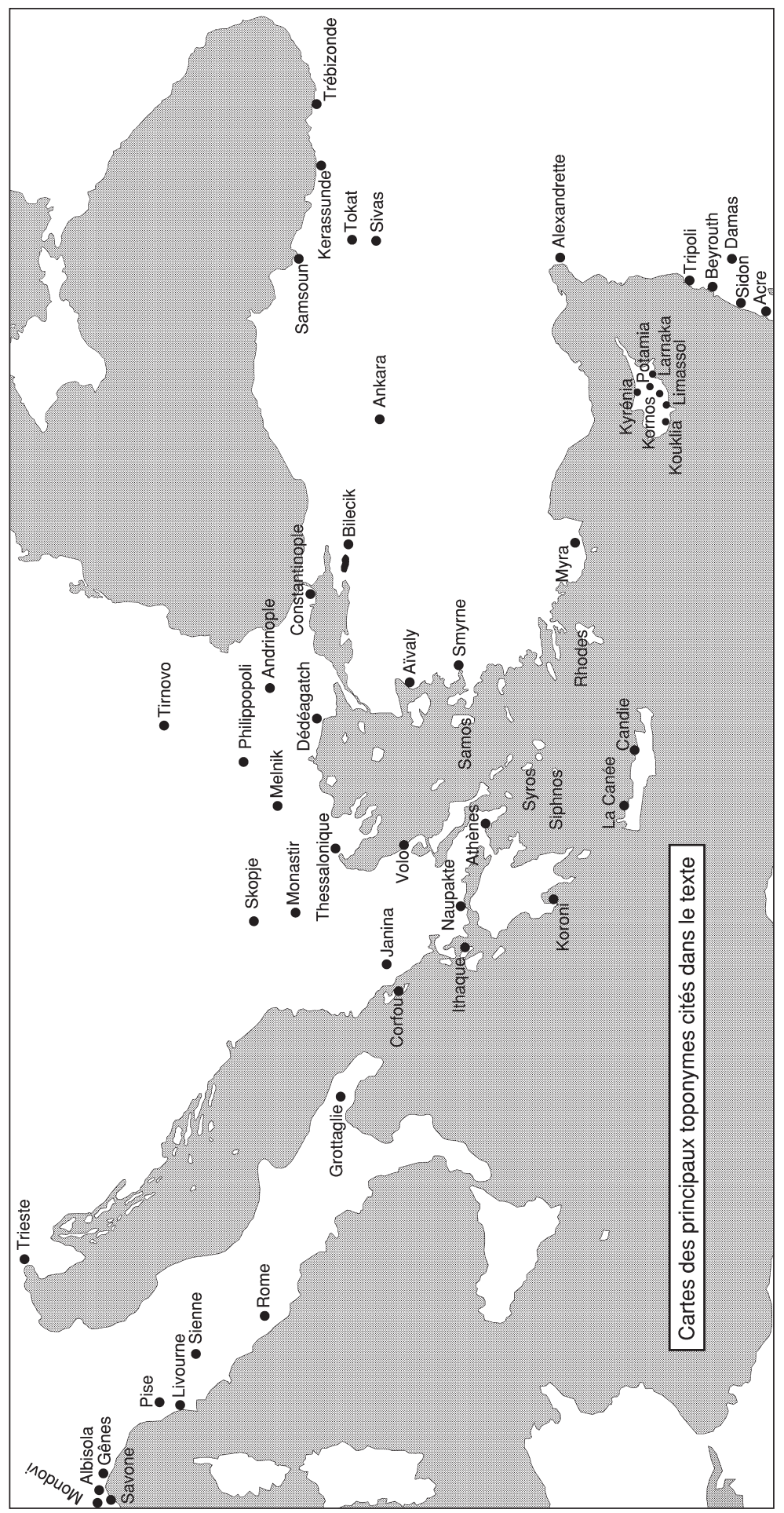


Véronique FrançOIS, Jarres, terrailles, faïences et porcelaines européennes dans l'Empire ottoman (XVIII ${ }^{e}$-XIX ${ }^{e}$ siècles)

Si les données livrées par les fouilles archéologiques sont encore insuffisantes pour obtenir une image précise du négoce de la vaisselle dans l'Empire ottoman aux $\mathrm{XVIII}^{\mathrm{e}}$ et $\mathrm{XIX}^{\mathrm{e}}$ siècles, les documents statistiques, les rapports des Expositions universelles, les textes consulaires, les «entrées» et les «sorties» des grands ports méditerranéens ainsi que les archives des manufactures européennes permettent de repérer les pays producteurs, d'appréhender les volumes et les prix des céramiques commercialisées, de connaître les ports d'embarquement, de transit et de débarquement, et de préciser les modes de diffusion. À partir de l'exploitation de ces archives commerciales, la présence, sur les territoires de la Sublime Porte - en Turquie d'Europe et d'Asie, dans les îles de l'Egée — de faïences fines, de porcelaines mais aussi de simples terres cuites produites dans les fabriques d'Europe, aux $\mathrm{XVIII}^{\mathrm{e}}$ et $\mathrm{XIX}^{\mathrm{e}}$ siècles, prend une toute autre ampleur. Contrairement à ce que les découvertes de terrain laissent croire, le commerce de la vaisselle européenne sur ces territoires n'est pas marginal, ce sont en fait des volumes importants qui sont importés d'Europe.

Véronique FrançoIs, European Jars, Earthenware, Faiences and China in the $X$ VIII $^{\text {th }}-X I^{\text {th }}$ Century Ottoman Empire

While the data resulting from archaeological excavations are still insufficient to get a precise idea of the pottery trade in the XVIIIth and XIXth century Ottoman empire, statistics, international exhibitions records, consular documents, the number of boats coming in and moving out of the chief Mediterranean ports, as well as records of European fabrics, enable us to locate the producing countries, evaluate the bulk and the price of the commercialised ceramics, to know which were the shipping, transit, and unloading ports and to specify the diffusion modes of these goods. Through the study of these commercial records it can be seen that the existence in the Porte territories -European and Asiatic Turkey, Aegean Islands- of delicate faience, chinaware, but also simple earthenware produced in European fabrics in the XVIIIth and XIXth century is quite important. Contrary to what we could be led to believe through the discoveries made on the spot, the trade of European crockery in these countries was in no means marginal, and as a matter of fact a great bulk of these goods was imported from Europe. 